\title{
An Assessment of Evaluation Practices of Low-And Moderate-Income Solar Programs
}

Bentham Paulos, Sydney Forrester, Eric O'Shaughnessy, Christopher Dyson, Galen Barbose, and Ryan Wiser

April 2021

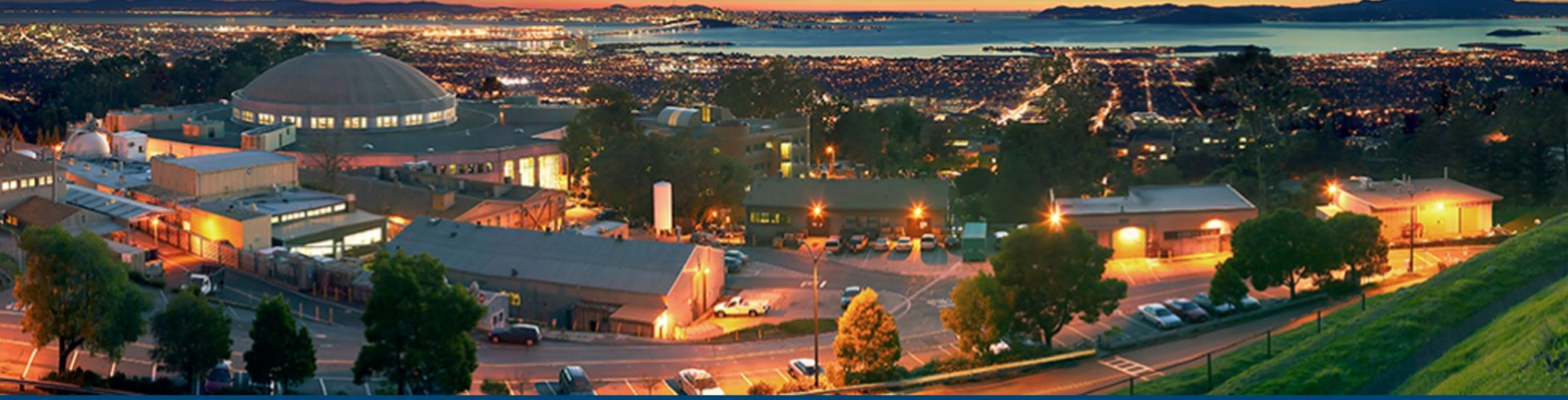




\section{Disclaimer}

This document was prepared as an account of work sponsored by the United States Government. While this document is believed to contain correct information, neither the United States Government nor any agency thereof, nor The Regents of the University of California, nor any of their employees, makes any warranty, express or implied, or assumes any legal responsibility for the accuracy, completeness, or usefulness of any information, apparatus, product, or process disclosed, or represents that its use would not infringe privately owned rights. Reference herein to any specific commercial product, process, or service by its trade name, trademark, manufacturer, or otherwise, does not necessarily constitute or imply its endorsement, recommendation, or favoring by the United States Government or any agency thereof, or The Regents of the University of California. The views and opinions of authors expressed herein do not necessarily state or reflect those of the United States Government or any agency thereof, or The Regents of the University of California.

Ernest Orlando Lawrence Berkeley National Laboratory is an equal opportunity employer.

\section{Copyright Notice}

This manuscript has been authored by an author at Lawrence Berkeley National Laboratory under Contract No. DE-AC02-05CH11231 with the U.S. Department of Energy. The U.S. Government retains, and the publisher, by accepting the article for publication, acknowledges, that the U.S. Government retains a non-exclusive, paid-up, irrevocable, worldwide license to publish or reproduce the published form of this manuscript, or allow others to do so, for U.S. Government purposes. 


\title{
An Assessment of Evaluation Practices of Low- and Moderate-Income Solar Programs
}

\author{
Prepared for the \\ Solar Energy Technologies Office \\ U.S. Department of Energy \\ Authors \\ Bentham Paulos, Sydney Forrester, Eric O'Shaughnessy, \\ Christopher Dyson (DNV GL), Galen Barbose, and Ryan Wiser \\ Ernest Orlando Lawrence Berkeley National Laboratory \\ 1 Cyclotron Road, MS 90R4000 \\ Berkeley CA 94720-8136
}

March 2021

The work described in this study was funded by the Solar Energy Technologies Office of the U.S. Department of Energy's Office of Energy Efficiency and Renewable Energy under Lawrence Berkeley National Laboratory Contract No. DE-AC02-05CH11231. 


\section{Acknowledgements}

This study was supported by the Solar Energy Technologies Office of the U.S. Department of Energy (DOE)'s Office of Energy Efficiency and Renewable Energy under Contract No. DE-AC02-05CH11231. We thank Ammar Qusaibaty, Michele Boyd and Becca Jones-Albertus, all of the U.S. DOE, for making the work possible. The early and frequent feedback provided by Ammar Qusaibaty was especially valuable in framing the study's objectives. We also thank the many low- and moderate-income solar program administrators listed below who provided feedback, through interviews, email requests, and other means. We thank Nate Hausman of the Clean Energy States Alliance and Tom Stanton of the National Regulatory Research Institute. Jarett Zuboy provided substantial editing assistance. Of course, any omissions or errors that remain are solely the responsibility of the authors.

Gwen Yamamoto-Lau, Hawaii Green Infrastructure Authority

Kelsey Read, Adele Andrews, and Sebastian Palthey-Glomeau, Massachusetts CEC

Laura Rigell, Philadelphia Energy Authority

Laura Oakleaf, Elevate Energy (Illinois Solar for All)

Daniel White and Emil King, DC Solar For All

Selya Price, Brian Garcia, Emily Basham, and Sergio Carillo, Connecticut Green Bank

David Comis, Maryland Energy Administration

Ariane Benrey, New Jersey Board of Public Utilities

Cathleen Monahan, GRID Alternatives 


\section{List of Acronyms}

DAC-SASH Disadvantaged Communities - Single Family Affordable Solar Housing

DiD differences-in-differences

GEM\$ Green Energy Money \$aver

HUD U.S. Department of Housing and Urban Development

LMI low- and moderate-income

MASH Multi-Family Affordable Solar Housing

PEA Philadelphia Energy Agency

SASH Single-Family Affordable Solar Housing

TTS Tracking the Sun 


\section{Table of Contents}

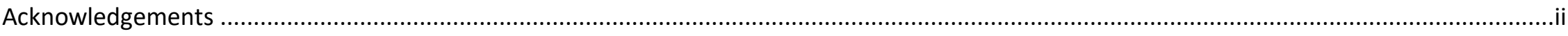

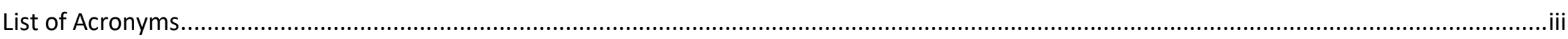

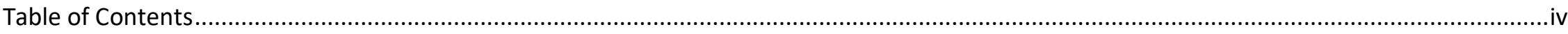

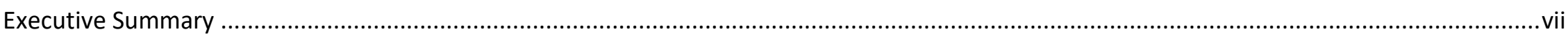

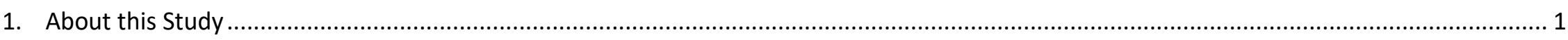

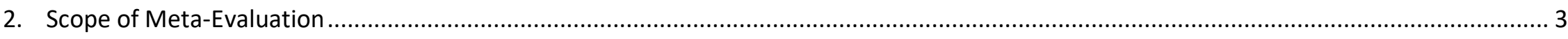

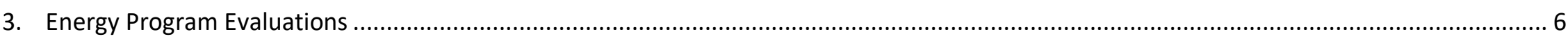

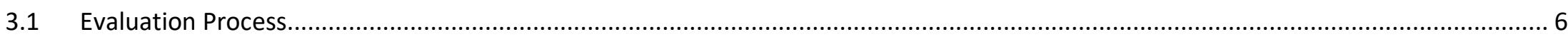

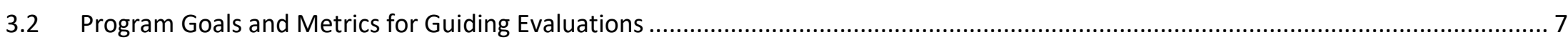

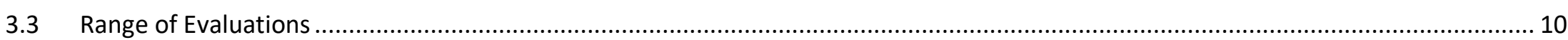

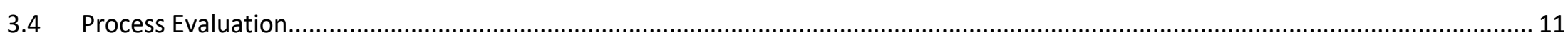

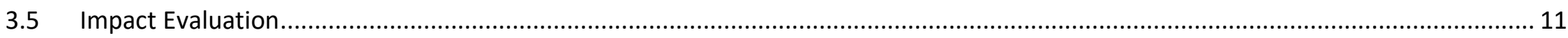

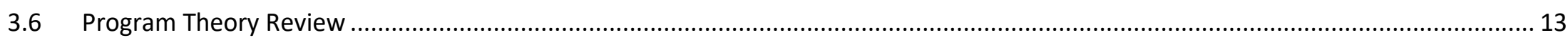

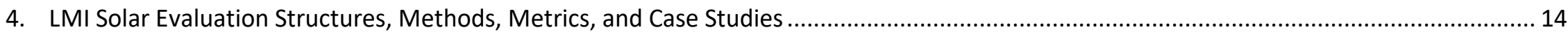

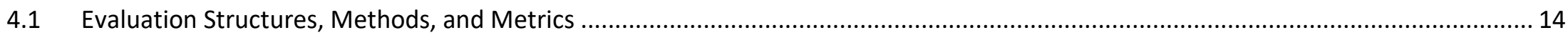

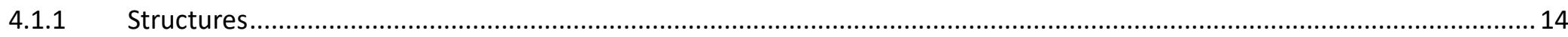

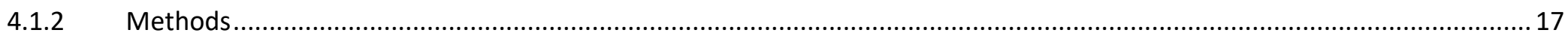

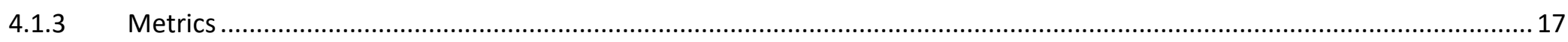

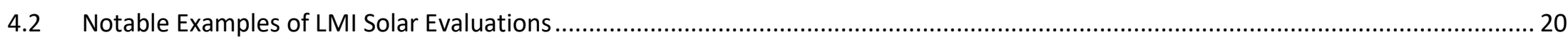

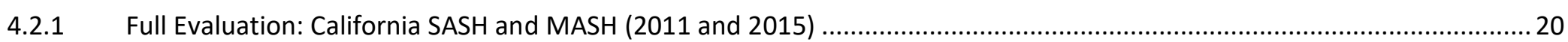

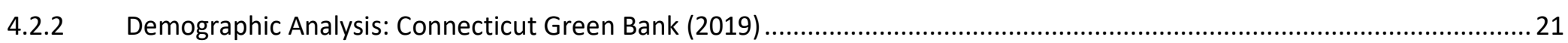

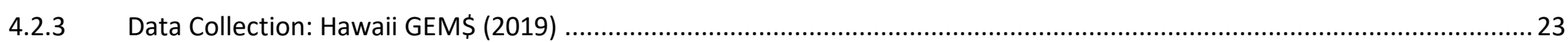

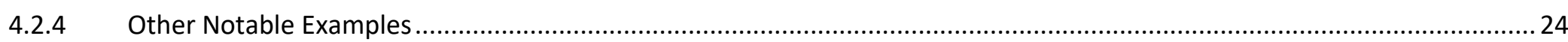

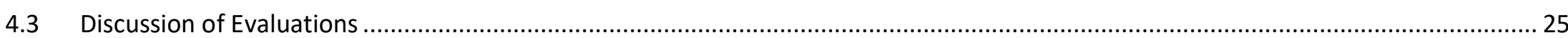




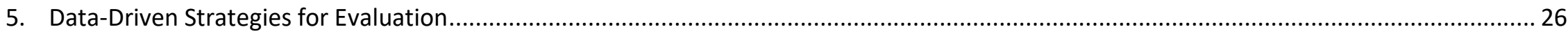

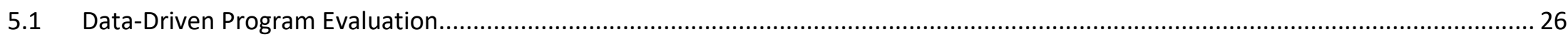

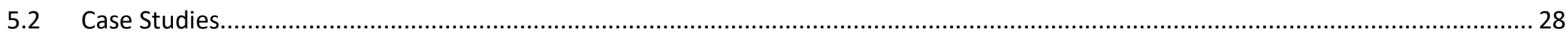

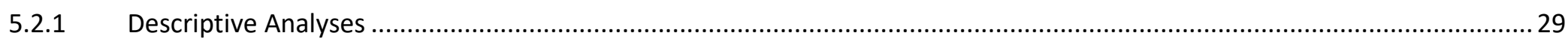

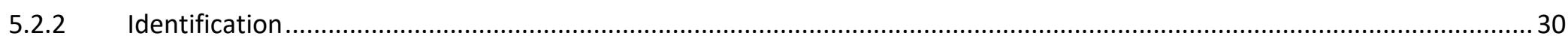

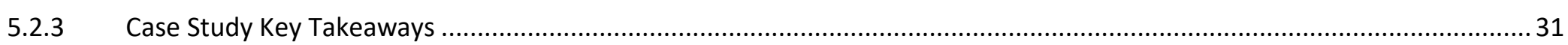

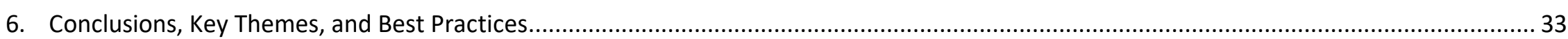

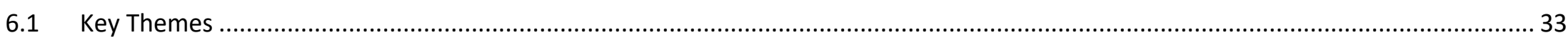

6.1.1 The majority of LMI solar programs do not have publicly-available evaluations ................................................................33

6.1.2 Some programs conduct progress reports, but few conduct true program evaluations ....................................................33

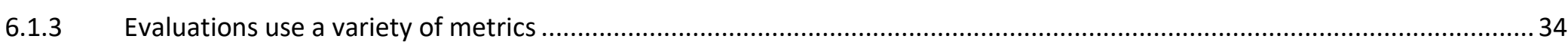

6.1.4 Programs vary in the extent to which data collection and evaluation are factored into program design .............................34

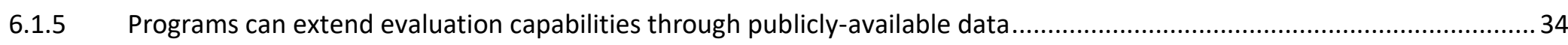

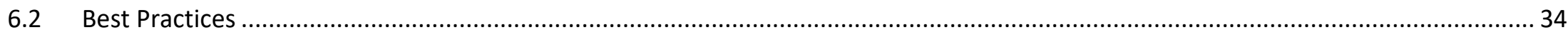

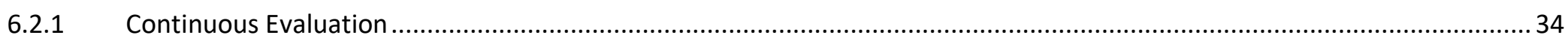

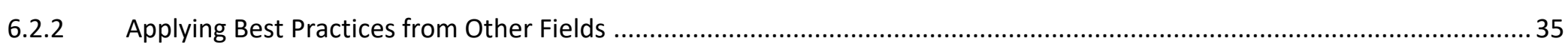

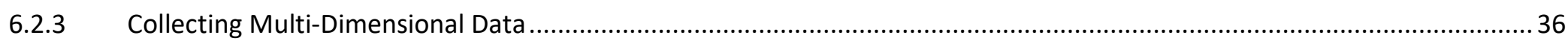

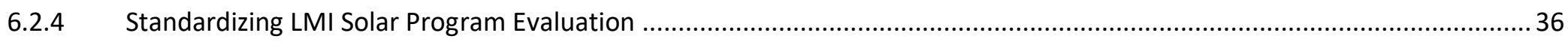

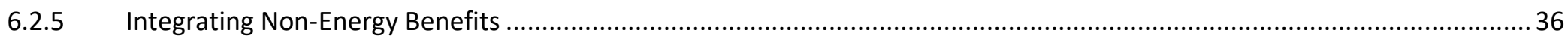

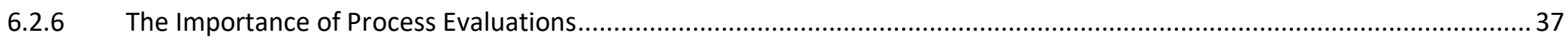

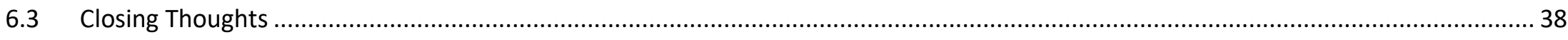

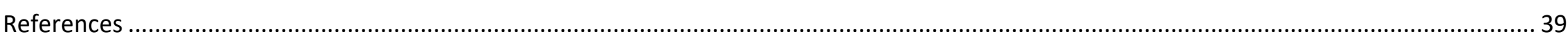

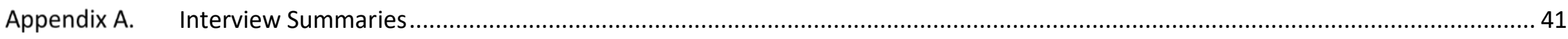

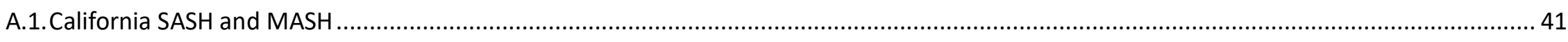

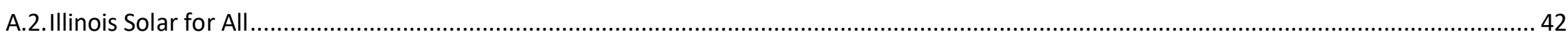

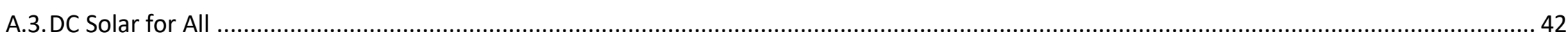

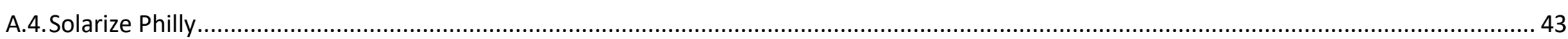


A.5. Mass Solar Loan

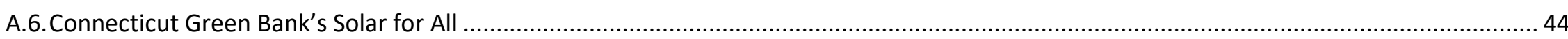

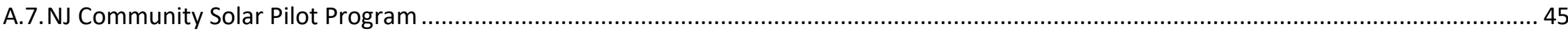

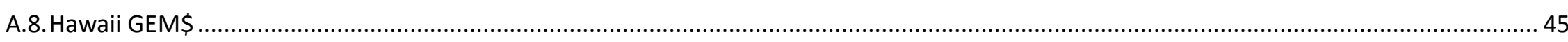

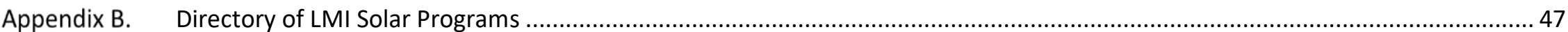

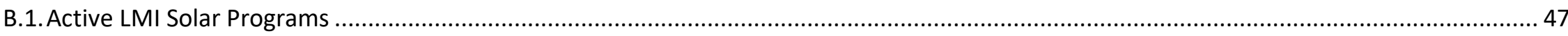

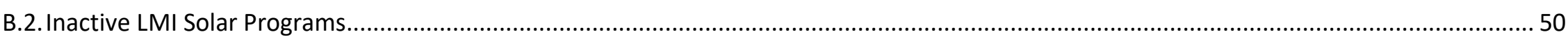

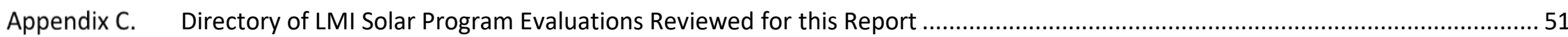

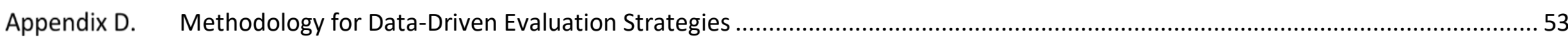

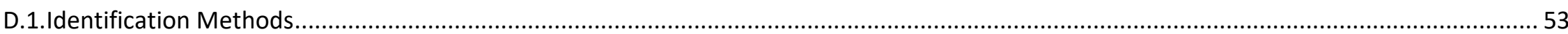

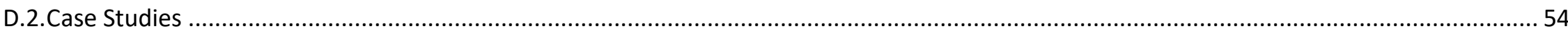




\section{Executive Summary}

A growing number of state and local governments, utilities, and non-profit organizations are interested in using solar power to reduce energy bills for low- and moderate-income (LMI) households, while meeting other policy goals such as job creation and clean energy promotion. In addition to programs that facilitate solar adoption by LMI households more generally (e.g., pay-as-you-save, PACE financing, non-LMI community solar), we identified 41 active programs that facilitate LMI adoption specifically through financing, upfront or production-based incentives, and mandatory set-asides for income-eligible households. These LMI solar programs generally operate on tight budgets and vary considerably in their design and stated goals. This puts a premium on program evaluation, to know what is working, what could be improved, and how to maximize program impacts under budget constraints.

In this study, we evaluate how LMI solar programs are being evaluated - that is, we meta-evaluate - in order to give insight to program administrators, policymakers, and stakeholders on best practices and key considerations. We identified $46 \mathrm{LMI}$ solar programs, 41 of which are currently active in 21 states. We collected evaluation and tracking documents from 16 of these programs, supplemented with interviews with 10 program administrators and evaluators.

We start with background information on how solar programs can address LMI household energy burdens. We then provide a brief discussion of the art and science of program evaluation, drawn from decades of experience in energy efficiency programs. We then turn to how LMI solar programs are currently being evaluated, highlighting trends among evaluation methods, metrics tracked, and best practices employed. We highlight a smaller subset to illustrate notable practices that could be applied to other program evaluations.

Our review of program evaluations and interviews with program stakeholders revealed five key themes:

\section{The vast majority of LMI solar programs do not have publicly-available evaluations}

Of the $46 \mathrm{LMI}$ solar programs identified across the U.S., only about one-third have created publicly-available evaluation documents. This could be due to a variety of reasons including the nascent stage or small size of some programs, budget constraints, or program administrators not separating out LMI-specific evaluations when LMI programs are part of larger solar programs.

\section{Most programs create progress reports, but few conduct true program evaluations}

Most programs conduct periodic progress reports summarizing basic metrics such as program expenditures and installed solar capacity. Of the programs with publicly-available evaluations, only 4 have done in-depth program evaluations that addressed both process and impact 
assessments in a rigorous way. The scarcity of in-depth program evaluations likely reflects program design and budget constraints.

\section{Evaluations use a variety of metrics}

LMI solar program evaluations describe program impacts using a variety of metrics. Of the 16 programs with published evaluations, the number of systems installed was the most common metric (16/16). Other common metrics included expenditures (13/16), jobs created (8/16), bill reduction (9/16), and system output (9/16).

\section{Programs vary in the extent to which data collection and evaluation are factored into program design}

Most LMI solar programs were designed without specific up-front plans for data collection or in-depth program evaluations. In contrast, a few programs were designed with very specific goals, and had specific up-front plans for periodic program evaluations, data collection, and data publication.

\section{Programs can extend evaluation capabilities by using publicly-available data}

Budget-constrained programs can extend their evaluation capabilities by coupling program data with publicly-available demographic and solar market data. For instance, a Connecticut program evaluation leveraged U.S. Census data to measure program impacts on LMI solar adoption. In Section 5 of this study, we summarize how other programs could apply similar methods.

Finally, we identified 6 best practices from our review of LMI solar program evaluations.

1) Continuous evaluation: Often evaluations are a "report card" at the end of a program. In contrast, ongoing evaluation can be used to guide continuous improvement, providing feedback during implementation. This requires planning ahead to collect and analyze data continuously.

2) Applying best practices from other fields: Energy efficiency programs can provide examples of best practices for program evaluation. Solar programs can draw from this history, such as specifying clear goals, developing a rigorous and testable theory of change, and sharing results with stakeholders.

3) Collecting multi-dimensional data: Collecting a broad set of program and participant data creates opportunities to look for correlations, which can provide greater insight into why a program is succeeding or failing.

4) Standardizing LMI solar program evaluation: Evaluation practices can be standardized and designed to work with smaller LMI solar programs, lowering costs and enabling comparisons. 
5) Integrating non-energy benefits: LMI solar programs can generate non-energy benefits such as improved wealth, health, and safety. Including these in evaluations is important to getting a full view of impacts and accurately tracking costs and benefits.

6) Process evaluations: Impact evaluations are often viewed as the bottom-line metric, but given the many variables of solar adoption, process evaluations can be better at explaining why customers respond or don't respond to programs, and why a program succeeds or fails.

For further reference, we provide appendices that present a directory with links to all 46 LMI solar programs with additional program details such as years of operation, sector, program elements, and eligibility criteria; links to the specific program evaluations that we reviewed across 16 programs; summaries of interviews with program administrators; and more details on the methodology of statistical evaluations.

In sum, our report is a meta-evaluation of LMI solar program evaluations. We ask how LMI solar programs are being evaluated, how those evaluations compare to best practices, and how program administrators could improve future evaluations. We find that while many programs conduct periodic progress reports, only a few have implemented in-depth evaluations. The lack of rigorous program evaluation likely reflects program design and budget constraints. We suggest that resource-constrained programs leverage publicly-available data to extend their evaluation capabilities, and consider the six best practices identified here to guide future LMI solar program evaluation. 


\section{About this Study}

Section summary: A growing number of states, municipalities, and utilities are exploring ways to facilitate LMI solar adoption. This study evaluates how those programs are being evaluated - a meta-evaluation. It aims to clarify the tradeoffs inherent in evaluation such that policymakers and program administrators can choose which approach is best for them.

The fraction of gross income dedicated to energy expenses, known as energy burden, is disproportionately large for low-to-moderate income (LMI) households (Bednar and Reames 2020; Brown et al. 2020). While there are many strategies to reduce LMI energy burden, solar has emerged as a potential solution as costs have fallen. Despite lower costs of solar adoption, LMI households remain significantly less likely to adopt than high-income households (Barbose et al. 2020). Today, a household earning more than $\$ 200,000 /$ year is about 4 times more likely to adopt solar than a household earning less than $\$ 50,000 /$ year (O'Shaughnessy et al. 2021). Barriers to going solar for LMI customers and communities include lack of capital, creditworthiness and financier risk perceptions, interest from marketers, homeownership, rooftop or electrical readiness, and difficulty monetizing federal tax incentives.

To mitigate solar adoption inequity, a growing number of states, municipalities, and utilities are adopting policies and programs to encourage the adoption of solar energy by LMI customers and communities. In addition to reducing energy burden, LMI solar programs are driven by a variety of motivations (Leon et al. 2019):

- Ensure that policies benefit people of all income levels, improve the resilience of vulnerable communities, redress past environmental injustices, and reduce exposure to pollution

- Help LMI residents build wealth at the household level as well as at the community level by providing jobs in under-resourced communities

- Reduce the long-term cost of energy-assistance programs and electricity shutoffs from non-payment

- Promote clean energy technologies and business practices

Previous research suggests that LMI solar programs can increase LMI solar adoption (O'Shaughnessy et al. 2021). However, there have been few program-level comparisons to understand the feasibility, effectiveness, and tradeoffs of specific program designs. To identify and prioritize effective LMI solar program design requires program evaluation. Program evaluation is a common component of energy programs-particularly energy efficiency programs. LMI solar programs have, to date, implemented a variety of program evaluation strategies with varying levels of rigor and completeness. 
The purpose of this study is to evaluate LMI solar program evaluation-that is, to meta-evaluate-to inform program administrators, policymakers, and stakeholders about how to provide actionable insights into LMI solar programs. Our meta-evaluation is based on collecting evaluation reports on $15 \mathrm{LMI}$ solar programs supplemented by interviews with 8 program administrators and evaluators. The study addresses fundamental questions about LMI solar program evaluations: How frequently are LMI solar programs evaluated? Are program designs and evaluations aligned with program goals and sizes? Are the programs supporting public policy goals? Are program administrators consistently collecting and analyzing data that are useful for tracking progress toward goals? Are LMI solar programs drawing from the best practices developed for energy efficiency program evaluation?

We begin by discussing the LMI solar programs considered (Section 2). We then summarize typical energy program evaluation principles, which have been traditionally used by energy efficiency programs, but could serve as a foundation for LMI solar evaluations (Section 3). Next, we present case studies of LMI solar program evaluation, highlighting both commonalities and differences across the range of evaluations, notable strategies some program administrators are employing, metrics tracked, and how administrators are grappling with program constraints (Section 4). We then examine data-driven strategies that combine internal program data with publicly available data to provide a low-cost way to expand the analytical rigor of evaluations. This may be especially useful for small programs with limited evaluation budgets (Section 5). Finally, we summarize key themes and draw conclusions about the state of LMI solar program evaluation (Section 6). Appendix A contains short summaries of interviews with program administrators. Appendix B provides a full directory of 41 active and 5 inactive LMI solar programs. Appendix C provides references and links to the specific LMI solar program evaluations that we reviewed across 16 programs. Appendix D contains notes on methods for the data-driven strategies.

Note that this study is strictly a meta-evaluation: a review and assessment of the evaluation practices of LMI solar programs. That is, we do not directly evaluate programs. In Section 5, we present program evaluation results for illustrative purposes only. Further, we do not attempt to compare LMI solar program evaluations against each other. Individual program evaluations must be understood in the context of programspecific constraints, particularly budgets. This study aims to clarify the tradeoffs inherent in evaluation such that policymakers and program administrators can choose which approach is best for them. 


\section{Scope of Meta-Evaluation}

Section summary: For the purposes of this study, an LMI solar program is a solar incentive program with explicit income qualifications. We identify 41 active and 5 inactive programs that meet these criteria.

For the purposes of this study, an LMI solar program is a solar incentive program with explicit income qualifications. Under these criteria, as of June 2020 we identified $46 \mathrm{LMI}$ solar programs, 41 of which are currently active or upcoming across 21 states (see Figure 1, with more details given in Appendix A). Included programs span all sectors and community solar, with at least one of three elements: subsidized finance (e.g., loans); direct financial incentives (e.g., upfront rebates or production-based incentives); or set-asides (e.g., program capacity or funds reserved for LMI households or communities). Many of these LMI solar programs were designed exclusively to serve LMI customers; however, some were designed as a subset of a broader program. While there are additional programs that may reduce barriers to LMI adoption (e.g., Property Assessed Clean Energy (PACE) or Pay-As-You-Save (PAYS) financing, incentives specific to multi-family building residents, etc.), we do not define these as LMI solar programs for the purposes of this review.

\begin{tabular}{|c|c|c|c|c|c|c|c|c|c|c|c|c|c|c|c|c|c|c|c|c|c|}
\hline & CA & CO & CT & DC & FL & HI & IL & MA & MD & MN & MS & NH & NJ & NV & NY & OR & PA & $\mathbf{R} \mathbf{I}$ & SC & VA & WA \\
\hline \multicolumn{22}{|l|}{ TARGET SECTORS } \\
\hline \multicolumn{22}{|l|}{ Single family } \\
\hline \multicolumn{22}{|l|}{ Multi-family } \\
\hline \multicolumn{22}{|l|}{ Community solar } \\
\hline \multicolumn{22}{|l|}{ PROGRAM ELEMENTS } \\
\hline \multicolumn{22}{|l|}{ Finance } \\
\hline \multicolumn{22}{|l|}{ Incentives } \\
\hline \multicolumn{22}{|l|}{ Mandatory set-aside } \\
\hline Number of active programs & 9 & 2 & 3 & 1 & 1 & 2 & 1 & 2 & 2 & 3 & 1 & 1 & 1 & 2 & 3 & 1 & 1 & 1 & 2 & 1 & 1 \\
\hline
\end{tabular}

Figure 1. LMI solar target sectors and program elements 
As shown in Figure 2, LMI solar programs date back to the mid-2000s, primarily in California, though the majority of programs have begun in the past decade across a more diverse set of geographies.

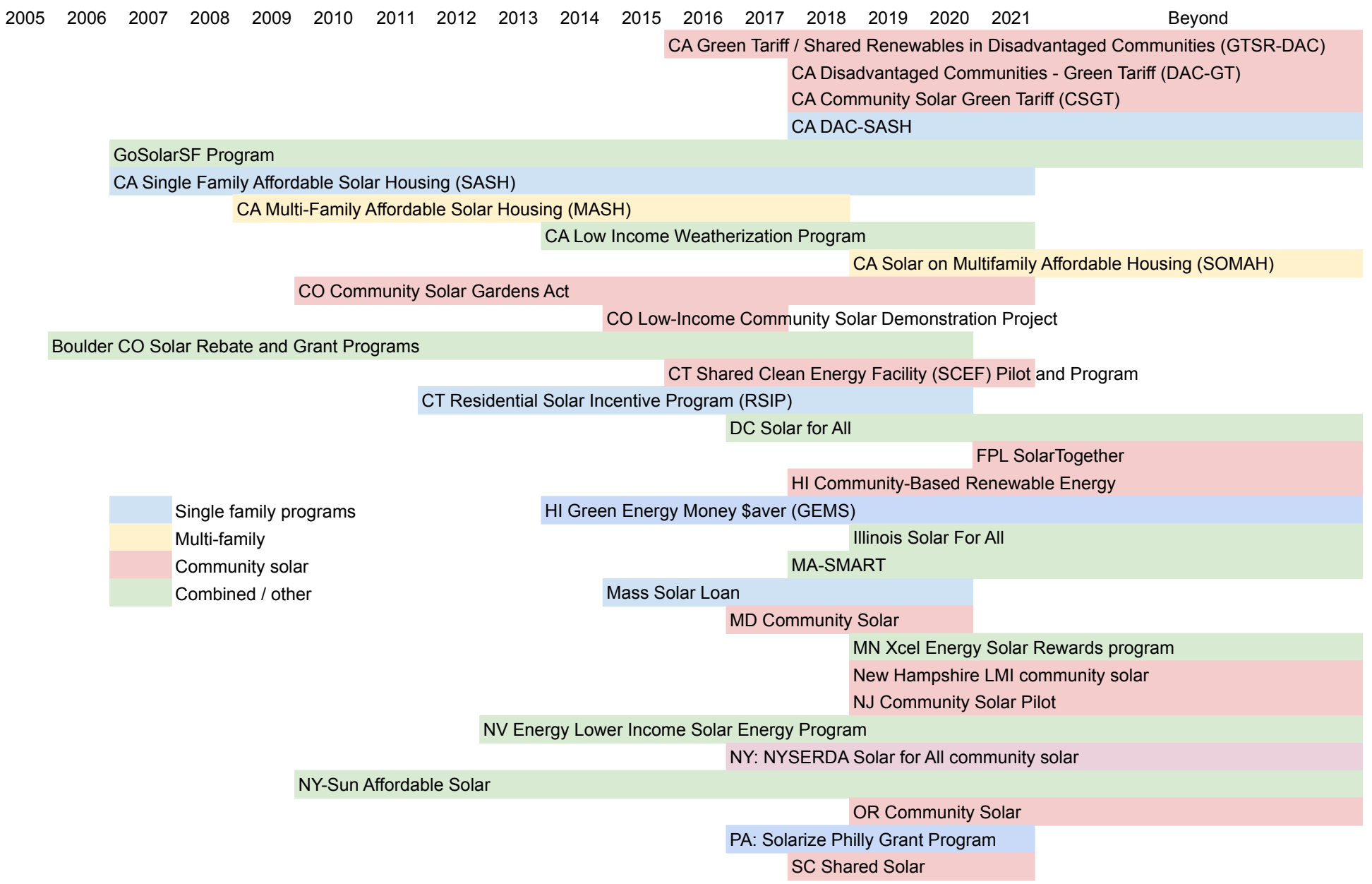

Figure 2. Timeline of LMI solar policies and programs 
LMI solar programs can be broadly categorized based on their target sectors. Single- and multi-family programs aim to incentivize solar deployment on houses and apartment buildings, where the benefits of adoption flow directly to the owners or tenants of the host buildings. Community solar programs distribute bill credits from a single shared system to a group of customers that "subscribe" to the system's output. Community solar, in particular, is a rapidly growing LMI solar program model. Community solar systems do not need to be sited on customer rooftops, making community solar an attractive option for LMI renters and LMI homeowners without suitable rooftops. As of late 2020, about 2.6 GW of U.S. community solar were installed (Heeter and Chan 2020) -though only a fraction of this capacity was reserved for LMI customers (Heeter et al. 2018). LMI-specific programs or mandatory set asides are becoming more common. Thanks to rapid adoption in recent years, LMI community solar programs are now active in 18 states, outnumbering programs encouraging on-site solar for single- and multi-family homes (Figure 1).

Of the programs we identified, we reviewed evaluations for 16. Only a few programs had been subject to a rigorous "full" evaluation, while others employed a range of methods with a range of depth and vigor. While most programs report process data in some form (such as number of rebates given), such reports do not provide much insight into the evaluation process, so not all were collected for this review. This could be due to a few different reasons. In some cases where the LMI solar program was a portion of a larger solar program, an LMI-specific evaluation may not be separated out from the larger program. In other cases where a program was new or in-progress, it may have been deemed too early to conduct an evaluation; it wasn't always clear if or when an evaluation would become available in the future. Finally, some programs may have had limited funding for evaluation and may not have been able to conduct a dedicated study. Regardless of the cause, we found that many of these programs had no publicly available tracking documents or evaluations. 


\section{Energy Program Evaluations}

Section summary: This section provides a brief introduction to energy program evaluation principles. We discuss the evaluation process, program goals and metrics, the different types of program evaluations (process and impact), and the principle of program theory review. For a more thorough introduction to energy program evaluation, see references in the literature, particularly Freeman et al. (2016).

\subsection{Evaluation Process}

A common process for program evaluation is displayed in Figure 3, adapted from (Freeman, Campbell, and Harms 2016). The schematic presents two types of program evaluation (see Sections 3.4-3.5) and four stages:

1) Planning: Preliminary planning helps align the evaluation with the goals of program, thereby ensuring the evaluation is asking the right questions and tracking the correct data to answer them. Once research objectives are determined, a data-collection plan is developed with a sample design to ensure that findings meet requirements for statistical precision.

2) Data collection: The evaluation team gathers evidence of the program's impacts by surveying program participants, inspecting installed equipment, and collecting energy data from participants and nonparticipants.

3) Analysis: Data are analyzed to answer the research questions identified in the planning stage.

4) Synthesis: Results are compiled and reported, including recommendations for program revisions and next steps.

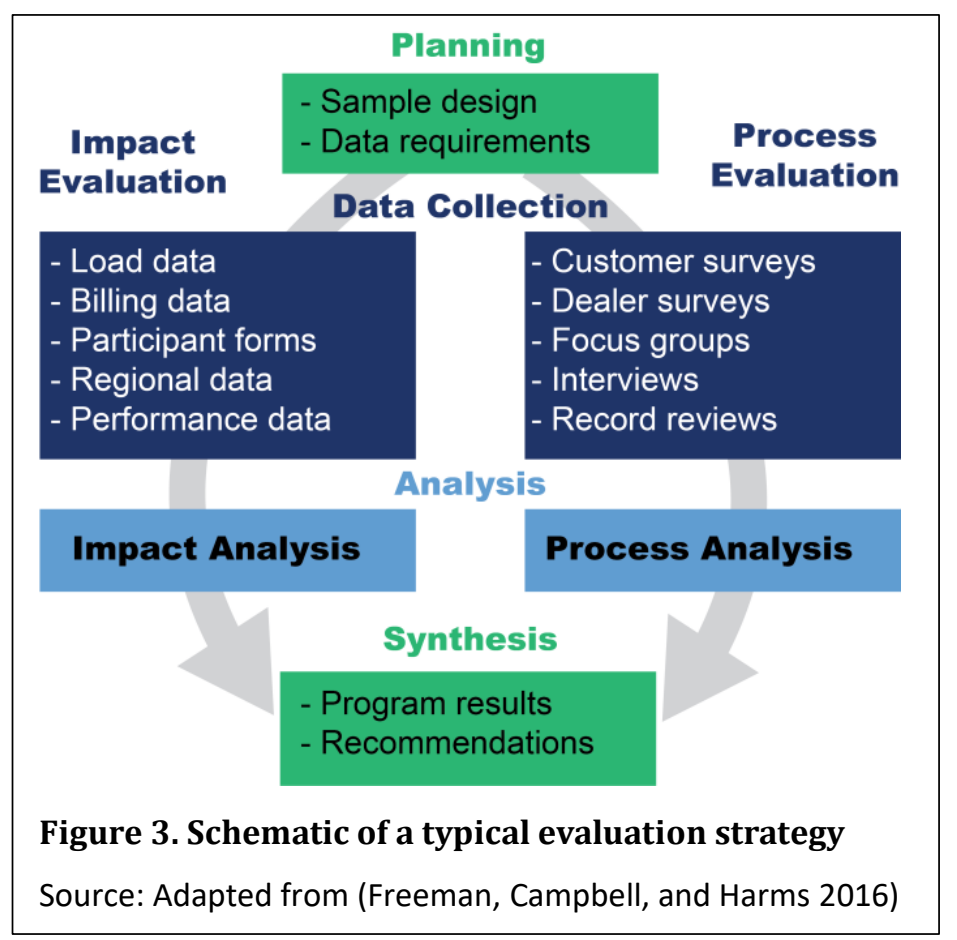

A key practical question in the evaluation process is whether evaluations are conducted internally by the program administrator, or externally by a hired third party. Each approach has pros and cons.

- Internal evaluations can be inexpensive and quick, delivering timely results. On the other hand, if an internal evaluation is not mandated, 
they may not be prioritized and are at risk of delay or cancellation. In addition, not recording or making the findings accessible to outside parties limits knowledge transfer. Lack of external sharing can also reduce accountability and responsiveness to suggestions for program improvements.

- External evaluations can provide greater objectivity and potentially tap the greater expertise of external evaluators who are familiar with lessons learned, program design, and best practices from similar programs. An external review is more likely to be part of a public process, with stakeholder input. On the other hand, external evaluations can be more expensive than internal evaluations, slower to produce findings, and involve less engagement from program staff, which can prevent staff from internalizing and "owning" the findings.

In both cases, the evaluation is only as good as the data availability allows, and only as thorough as expertise and budget allow (Freeman, Campbell, and Harms 2016).

A final key point in terms of process is that evaluations can be vehicles for continuous improvement. As shown in Figure 4, evaluation findings can feed back into all aspects of planning, design, and implementation, as well as overarching policy and resource planning (Schiller 2012). Evaluations can be more effective and cost-effective if plans are built into a program from inception, just as objectives, design, and implementation are.

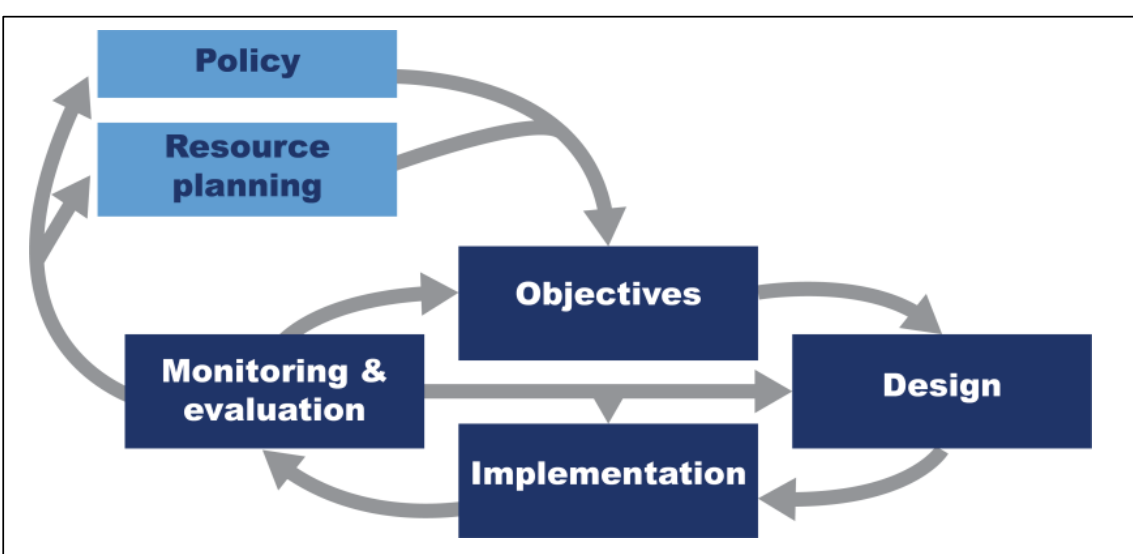

Figure 4. Cycle of program planning, implementation, and evaluation

Source: Adapted from (Schiller 2012)

\subsection{Program Goals and Metrics for Guiding Evaluations}

While LMI solar programs generally aim to benefit LMI customers, the specificity and measurability of the goals vary by program. Goals can also evolve during program execution. Because evaluations typically measure progress against program goals, the precision, clarity, and durability of those goals can affect the rigor and value of the program evaluation. Text Box 1 lists examples of LMI solar program goals (emphasis added). 
Text Box 1: Sample LMI Solar Program Goals

\section{Illinois Solar for All}

"Maximize the development of new photovoltaic generating facilities, create a long-term, low-income solar marketplace throughout the State, integrate with existing energy efficiency initiatives, and minimize administrative costs."

\section{Washington DC Solar For All}

"Solar for All's specific targets are to provide the benefits of solar energy to 100,000 low-income households (defined as households at or below $80 \%$ of Area Median Income) and to reduce their energy bills by $50 \%$ (based on the residential rate class average usage for 2016) by 2032."

\section{California SOMAH}

a. Provide assistance to low-income utility customers to make sure they can afford to pay their energy bills.

b. Reduce the costs of the energy utilities' California Alternate Rates for Energy, or CARE, program [to] support the long-term ability of the CARE program to meet the needs of low-income customers.

c. Provide local economic development benefits while advancing the state's renewable energy policies and policies to reduce emissions of greenhouse gases.

d. Provide benefits to disadvantaged communities.

e. Make qualifying solar energy systems more accessible to low-income and disadvantaged communities and ... to install those systems in a manner that represents the geographic diversity of the state.

f. To install qualifying solar energy systems that have a generating capacity equivalent to at least 300 megawatts for the express purpose of lowering the energy bills of tenants at low-income multifamily housing. 
Program goals imply certain metrics, and goals and metrics in turn guide program evaluations. Table 1 lists sample goals from LMI solar programs along with metrics that can be used to measure progress toward those goals.

Table 1. Examples of Program Goals and Corresponding Metrics

\begin{tabular}{|l|l|}
\hline Program Goal & Metrics \\
\hline $\begin{array}{l}\text { Ensure solar policies benefit people and } \\
\text { communities of all income levels and } \\
\text { demographics }\end{array}$ & $\begin{array}{l}\text { Participation levels and benefits by category of interest (e.g., } \\
\text { solar installations in certain zip codes) }\end{array}$ \\
\hline $\begin{array}{l}\text { Reduce energy bills and burdens, exposure to } \\
\text { rate increases }\end{array}$ & Energy bill size and savings, household income \\
\hline Create economic opportunity and jobs & $\begin{array}{l}\text { Household wealth (such as home value), jobs created, job } \\
\text { training participants, job retention, placement of trainees, } \\
\text { income }\end{array}$ \\
\hline $\begin{array}{l}\text { Transform solar markets to better serve LMI } \\
\text { customers }\end{array}$ & $\begin{array}{l}\text { Number of solar companies and lenders serving LMI households, } \\
\text { marketing strategies, business models, geospatial solar adoption }\end{array}$ \\
\hline Reduce operating costs for social service agencies & Bill savings for agencies, funds redirected to core mission \\
\hline Reduce the cost of bill assistance programs & Impact on rate discount programs \\
\hline Address environmental and social injustices & $\begin{array}{l}\text { Project development in disadvantaged communities, reduced } \\
\text { pollution, increased jobs and revenues }\end{array}$ \\
\hline Overcome barriers to participation & $\begin{array}{l}\text { Identify and measure specific barriers (e.g., finance, tenancy, } \\
\text { awareness) }\end{array}$ \\
\hline
\end{tabular}




\subsection{Range of Evaluations}

Evaluations vary in scope, from examining the internal processes of the program manager to analyzing impacts on participants, nonparticipants, the utility, the marketplace, or the local economy. While evaluation methods have been highly refined over the years, not all evaluations follow the best practices manuals to a letter. Evaluations can be thought of falling along a spectrum, from basic to in depth (Figure 5). The most basic LMI solar program evaluations simply track progress, which may include the number of vendors participating, rebates given, and eligibility of customers served. Evaluations that are more thorough look at impacts, such as quantifying and verifying outcomes, comparing costs and benefits from various perspectives, and assessing the program's market context and broader impacts. The most rigorous and complete types of these we call full evaluations; they are often done by an independent third party, relying on both internal program data and newly collected analysis, and follow detailed EM\&V protocols.

In each case, the evaluation scope should align with program goals and metrics. For example, for programs where market transformation is an explicit program goal, additional metrics on non-participants or overall market adoption patterns must be intentionally collected, tracked, and measured. An evaluation can also attempt to measure "spillover" effects, looking to see if the measures are leading non-participants to change their behavior or purchasing decisions.

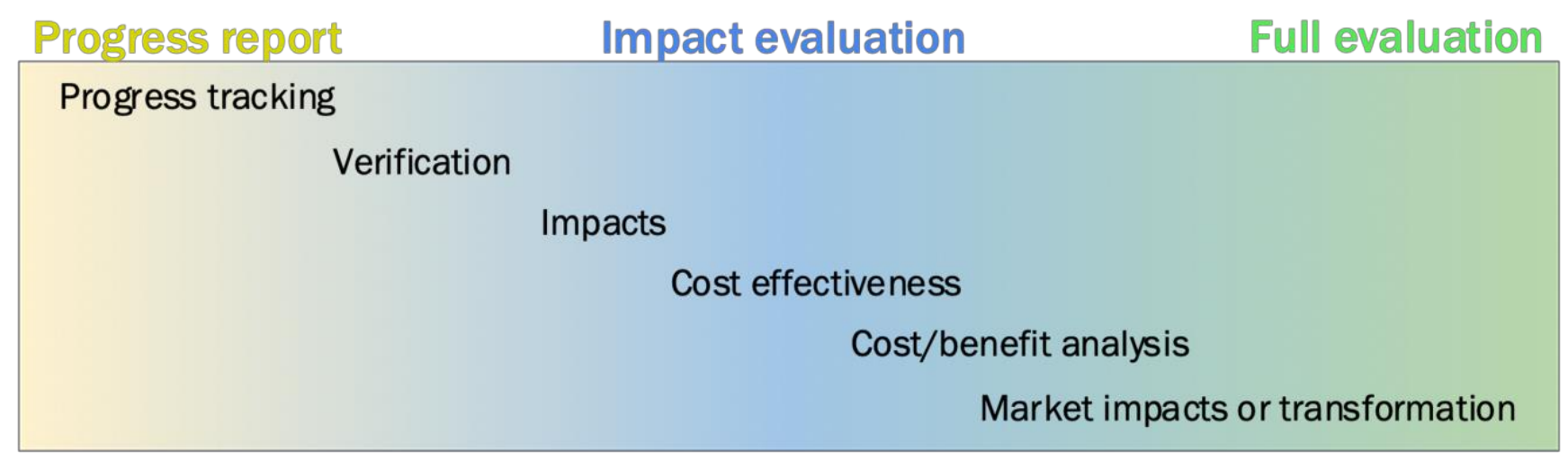

Figure 5. Range of evaluations 


\subsection{Process Evaluation}

Process evaluations examine program efficacy and stakeholder feedback with a primary objective of refining program design and processes, increasing cost-effectiveness and program participation, and improving the satisfaction of customers, vendors, and other stakeholders.

Evaluating a process can include collecting best practices from other jurisdictions to identify gaps, collecting cost data to inform benefit/cost calculations, and collecting data on market characteristics and industry standard practices. A process evaluation can entail interviews or focus groups with participants, vendors, or others; surveys; and collection and analysis of process data. Process metrics vary according to the program and its goals. These metrics can include the number and disposition of applications, and the speed and cost of processing them; trends in participation by customers, trade allies, and other stakeholders; and favorability or customer satisfaction scores.

\subsection{Impact Evaluation}

Impact evaluations pertain more to achieving goals: gauging program effectiveness in terms of energy and non-energy benefits, justifying expenses via cost-benefit analysis, and studying non-participant and market effects. In some cases, these evaluations can be used to determine program cost recovery and assess whether to continue or revise a program. Evaluating the impacts can include collecting data through telephone or online surveys, site visits, and energy meters; using engineering algorithms to estimate energy savings ("deemed savings"); applying statistical or econometric analysis; and performing market studies. Outcome metrics can include the number of installations, dollars spent, and energy produced; bill savings and impacts on energy burdens; pollution reduction; and job training and creation.

One key impact evaluation method is a market impact assessment, which measures technology adoption patterns, behaviors, and market impacts among a broader population than those directly impacted by the program. These studies help evaluators attribute impacts to the program, differentiated from naturally occurring market trends.

Another key impact evaluation method is cost-effectiveness testing, which includes a refined set of tests for energy program evaluation (Table 2). Evaluations can measure benefits and costs from different perspectives via five main tests that include a participant cost test, program administrator cost test, ratepayer impact measure, total resource cost test, and societal cost test (US EPA 2008). 
Table 2. Five Principal Cost-Effectiveness Tests Used in Energy Efficiency

\begin{tabular}{|l|l|l|}
\hline Test & Key Question Answered & Summary Approach \\
\hline Participant cost test (PCT) & $\begin{array}{l}\text { Will the participants benefit over } \\
\text { the measure life? }\end{array}$ & $\begin{array}{l}\text { Comparison of costs and benefits of the customer } \\
\text { installing the measure }\end{array}$ \\
\hline $\begin{array}{l}\text { Program administrator } \\
\text { cost test (PACT) }\end{array}$ & Will utility bills increase? & $\begin{array}{l}\text { Comparison of program administrator costs to supply- } \\
\text { side resource costs }\end{array}$ \\
\hline $\begin{array}{l}\text { Ratepayer impact } \\
\text { measure (RIM) }\end{array}$ & Will utility rates increase? & $\begin{array}{l}\text { Comparison of administrator costs and utility bill } \\
\text { reductions to supply-side resource costs }\end{array}$ \\
\hline $\begin{array}{l}\text { Total resource cost test } \\
\text { (TRC) }\end{array}$ & $\begin{array}{l}\text { Will the total costs of energy in the } \\
\text { utility service territory decrease? }\end{array}$ & $\begin{array}{l}\text { Comparison of program administrator and customer } \\
\text { costs to utility resource savings }\end{array}$ \\
\hline Societal cost test (SCT) & $\begin{array}{l}\text { Is the utility, state, or nation better } \\
\text { off as a whole? }\end{array}$ & $\begin{array}{l}\text { Comparison of society's costs of energy efficiency to } \\
\text { resource savings and non-cash costs and benefits }\end{array}$ \\
\hline
\end{tabular}

Using different tests and perspectives can deliver different results. A relatively high-cost measure that delivers large pollution reductions, for example, may deliver positive results for society but may not be economically positive for the participant. A measure that cuts energy demand during times of utility-coincident peaks may deliver greater benefits to the utility (under a total resource cost test) than to a participant who is on a flat retail electricity rate.

Although these tests are common in energy efficiency program evaluation, few LMI solar evaluations have used them to date. In general, when benefits are narrowly framed, LMI-focused programs often appear less economically attractive than non-LMI programs. That said, LMI solar and energy efficiency programs generate non-energy benefits that are not always captured by standard evaluation tests. Non-energy benefits can include household improvements such as increased comfort, societal gains such as pollution reduction, or economic benefits such as increased household net income (Tonn et al. 2014). Though much work has been done in recent years to improve ways of measuring these effects, experience has shown that some non-energy benefits can be difficult to quantify and monetize (Sutter et al. 2020). Nonetheless, including nonenergy benefits can affect the cost-benefit calculation of energy programs. Among the LMI solar program evaluations reviewed later, this was only done fully for 2 of the 16 programs-in those two cases, demonstrating improvements in both utility and participant cost effectiveness. 


\subsection{Program Theory Review}

An important part of an evaluation can be to clarify and test a program's theory of change, also known as a "program theory" or "logic model." A program theory "tells the story of a program": What does the program do to deliver the outcomes desired? Fundamentally, the theory could describe an action taken to overcome a barrier to achieve an outcome. Starting with underlying theory enables the evaluation to determine whether a program fails owing to poor implementation or poor design (Freeman, Campbell, and Harms 2016). The theory may be especially important for relatively new or experimental LMI solar programs, because "many of the cause-and-effect relationships might be relatively untested and implementation problems are more numerous" (Freeman, Campbell, and Harms 2016).

A review of the program theory can guide the evaluation by asking questions such as:

- What outcomes is the program trying to achieve?

- Has the program identified the market barriers it is trying to overcome?

- Is the program effectively designed to lower these market barriers?

- What metrics are used to measure whether the program is lowering these barriers?

- Does the program design account for possible external factors and influences?

- Are key stakeholder interests reflected in the program design?

A coherent program theory helps the program administrator know which metrics or key performance indicators are the best measurements of program success, and thus which data must be collected from the very beginning of the program. Many program failures can be traced back to flaws or gaps in program theory, as when the program design did not reflect true market operation, it overlooked or underestimated market barriers or the interests of key stakeholders, or it had other failings. 


\section{LMI Solar Evaluation Structures, Methods, Metrics, and Case Studies}

Section summary: Of the $46 \mathrm{LMI}$ solar programs we identified, 16 have published program evaluation documents. In this section, we review the structures, methods, and metrics used in those 16 program evaluations, and discuss some notable examples of LMI solar program evaluations. We find that many programs (30/46) have not published LMI solar program evaluations, and of the programs that have published evaluations only 4 have conducted in-depth program evaluations comparable to evaluations in the field of energy efficiency.

Though we were able to identify 46 LMI solar programs (Appendix B), we reviewed publicly available evaluations and progress reports from 16 LMI solar programs in the United States (Table 3; see also Appendix C for references and weblinks). The evaluations ranged widely across several dimensions: whether they were done by internal vs. external analysts, what metrics were tracked, and whether they were annual progress filings, one-time evaluations, or iterative analyses.

In this section, we describe commonalities and differences among LMI solar program evaluations, focusing on how evaluations were structured, methods of data collection and evaluation, metrics tracked, etc. We then explore several illustrative evaluations in further depth.

\subsection{Evaluation Structures, Methods, and Metrics}

\subsubsection{Structures}

Of the 16 programs, very few produced evaluations similar to the format typical of energy efficiency programs. As a result, we use the term evaluations to encompass the full range of documents described in Section 3. We broadly group evaluation structures into three categories: progress reports (often filed for regulatory compliance), impact reports, and full evaluations. We did not include in our review programs that reported only the most basic metrics, such as funds expended, or that have not yet performed evaluations.

Half (8) of the evaluation documents that we collected were progress reports, the simplest form. These documents tended to report program money spent, money remaining, and some metric of progress (e.g., dollars in financing allocated, total kilowatts of solar deployed, number of customers served, number of systems built, loans executed). Often these reports followed a set filing frequency (e.g., annual or quarterly), were performed internally, and relied solely on program documentation and tracking databases.

Three programs developed supplemental impact reports, which were often a one-time analysis that took a snapshot of the program's impact on 
participating customers and/or the market as a whole. This typically involved survey analysis and focused on metrics such as bill reduction, customer satisfaction, and adoption patterns by demographic characteristics. These impact reports usually drew on relatively small sample sizes.

Only four of the 16 programs developed full evaluations comparable to traditional energy efficiency program evaluations. The full evaluations were performed independently by third parties and were iterative, with feedback loops to improve the programs as lessons were learned. These full evaluations were more likely to have well-defined goals and accompanying metrics to understand a program's impact. Evaluators drew on multiple information sources including program documents and databases, customer surveys, and desk and field verification of completed projects. In some cases, they used field data to test the reliability of predictive models of program impacts such as bill reduction and solar production. More so than the progress reports or one-time impact reports, these evaluations encompassed both process and impact assessments more consistent with those described in Section 3. These iterative, full evaluations better reflect program impacts as well as provide iterative improvements on process and program design, however, likely necessitate dedicated funding to ensure consistent analysis. 
Table 3. Evaluation Structures and Methods, Organized by Review type

\begin{tabular}{|c|c|c|c|c|c|c|c|}
\hline \multirow[b]{3}{*}{ Programs } & \multirow[b]{3}{*}{$\begin{array}{l}\text { Third-Party } \\
\text { Evaluation }\end{array}$} & \multirow[b]{3}{*}{ Evaluation Type } & \multirow[b]{3}{*}{ Frequency } & \multicolumn{4}{|c|}{ Tracking/Evaluation Methods } \\
\hline & & & & \multicolumn{2}{|c|}{ Impacts } & \multicolumn{2}{|c|}{ Quality Assurance } \\
\hline & & & & $\begin{array}{l}\text { Program } \\
\text { Documents }\end{array}$ & $\begin{array}{l}\text { Interview/ } \\
\text { Survey }\end{array}$ & $\begin{array}{c}\text { Desk } \\
\text { Verification }\end{array}$ & $\begin{array}{c}\text { Field } \\
\text { Verification }\end{array}$ \\
\hline CA: DAC-SASH & & Progress report & 6 months & $x$ & $x$ & $x$ & $x$ \\
\hline CA: Green Tariff Shared Renewables & & Progress report & 1 year & $x$ & & & \\
\hline $\begin{array}{l}\text { CT: Res. Solar Investment Prog. (LI Sub- } \\
\text { Progs.) }\end{array}$ & $x$ & Progress report & One-time & $x$ & & & \\
\hline DC: Solar For All & & Progress report & 1 year & $x$ & & & \\
\hline HI: Green Energy Money \$aver & & Progress report & 3 months & $x$ & & & \\
\hline MN: Solar Rewards & & Progress report & 1 year & $x$ & & & \\
\hline NJ: Community Solar Energy Pilot & & Progress report & One-time & $\mathrm{x}$ & & & \\
\hline NY: NY Sun Low Income Sub-Programs & & Progress report & One-time & $\mathrm{x}$ & & $\mathrm{x}$ & $\mathrm{x}$ \\
\hline $\begin{array}{l}\text { CA: Low-Income Weatherization } \\
\text { Program }\end{array}$ & & Impact report & One-time & $x$ & $\mathrm{x}$ & & \\
\hline CO: Solar Gardens & $x$ & Impact report* & One-time & $x$ & $x$ & & \\
\hline $\begin{array}{l}\text { CO: Low Income Community Solar } \\
\text { Demo }\end{array}$ & $\mathrm{x}$ & Impact report & One-time & $\mathrm{x}$ & $\mathrm{x}$ & & \\
\hline NH: LMI Community Solar Projects & & Impact report & One-time & $\mathrm{x}$ & $\mathrm{x}$ & & \\
\hline CA: SASH & $x$ & Full evaluation & 2 years & $x$ & $x$ & $x$ & $x$ \\
\hline CA: MASH & $x$ & Full evaluation & 2 years & $\mathrm{x}$ & $\mathrm{x}$ & $x$ & $\mathrm{x}$ \\
\hline $\begin{array}{l}\text { CA: Solar on Multifamily Affordable } \\
\text { Homes }\end{array}$ & $\mathrm{x}$ & Full evaluation** & TBD & $x$ & $\mathrm{x}$ & & \\
\hline IL: Solar For All & $x$ & Full evaluation** & 2 years & $x$ & $x$ & $x$ & $\mathrm{x}$ \\
\hline
\end{tabular}

* Additional to progress report

** First-year evaluation with indication of being more thorough in future iterations 


\subsubsection{Methods}

At a minimum, each program collected documents related to how funding was allocated, participant numbers or subscriptions, cost and number of installations, etc. that went towards progress reports and regulatory filings. In many cases, program administrators aggregated information from portals or databases that approved installers would use to submit required data. For programs that only conducted progress reports and compliance filings, these data were oftentimes simply summarized and reported. Of the 8 programs that produced progress reports, 6 relied solely on summarizing these databases. Additionally, six programs only conducted one evaluation. Periodic and standardized data collection and review allows for tracking a program's impacts over time, whereas one-time or inconsistent reviews may only offer a snapshot or partial insight.

Slightly over half of the evaluations (9/16) used interviews and surveys to get a better understanding of participant, administrator, and/or installer experience. Of note, all impact reports and full evaluations utilized these methods, but only one progress report did so. Evaluations that leveraged this kind of feedback are better able to understand more qualitative aspects of the LMI solar program such as motivation for participating, satisfaction with the program, non-energy benefits realized, and critiques. Where used effectively, results can help to identify what worked well and what did not in order to iterate on program design. In some cases, program administrators were able to target specific questions towards problems that they were experiencing (e.g., barriers of subscriber acquisition) to better present solutions. Finally, some evaluators employed random sampling in order to collect feedback representative of the entire group.

Five of the evaluations used field and desk verification. This was done for some progress reports for quality assurance and as a way to ensure proper installation and interconnection. However, in the case of full evaluations, evaluators were more likely to go beyond simple quality assurance and collect data to improve their understanding on participant impact. Full evaluations utilized random sampling techniques and recorded solar production data to understand solar performance compared to what was anticipated before construction. In the case of California's singe family (SASH) and multi-family (MASH) programs, evaluators collected data to train a predictive model used to quantify program impact on participant bills

\subsubsection{Metrics}

Metrics varied widely between evaluations. We grouped these into categories that include basic tracking, participant income, energy impact, market analysis, cost-benefit tests, quality assurance and feedback (Table 4).

In general, progress reports focused on funds allocated and compliance metrics such as costs, remaining budget, participation numbers, and installed capacity. While this may align with program goals that may have only specified a desired increase in LMI solar access or dollars spent in 
LMI communities, programs with more detailed goals (e.g., reduced energy burden, job creation, peak load reduction, etc.) tended to expand their tracked metrics.

Additionally, some programs were able to translate tracking data such as installed capacity into metrics such as bill reduction or energy bill reduction via in-house modeling. These reported numbers, although modeled, were created by collecting training data via quality-assurance field and desk validations of specific customer bill changes and/or specific solar system production.

Some reports mentioned non-energy program benefits. However, in many cases the reports noted that these non-energy benefits were difficult to quantify and could only be documented qualitatively through surveys with participating customers. In only one case (California's SASH and MASH) were non-energy benefits to the participant and utility quantified. Other evaluators indicated interest in quantifying these benefits and reporting them in future evaluations.

Some impact and full analyses went beyond participant and program administrator impacts to examine market impacts. This included looking at the demographics of adoption patterns compared to the population as a whole or better understanding enrollment in other LMI programs that could indicate the pool of other income-eligible customers.

Other metrics sometimes assessed include:

- Energy impact calculations where evaluations simulated solar production from installed systems and, in some cases, compared the coincidence with system peaks.

- Cost-benefit tests to better understand the economic value of the program from multiple perspectives.

- Realization rate calculations, which compared actual solar output to modeled results.

- Process feedback where stakeholders provided feedback on the programs and on how the evaluations were performed-including which aspects of program delivery were working well, which could be improved, and any program metrics that should be tracked. 
Table 4. Evaluation Metrics

\begin{tabular}{|c|c|c|c|c|c|c|c|c|c|c|c|c|c|c|c|}
\hline & \multicolumn{4}{|c|}{ Basic Tracking } & \multicolumn{3}{|c|}{ Participant Impact } & \multicolumn{2}{|c|}{$\begin{array}{l}\text { Energy } \\
\text { Impact }\end{array}$} & \multicolumn{3}{|c|}{ Market Analysis } & \multirow{2}{*}{$\begin{array}{l}\text { Cost-Benefit Test } \\
\text { (e.g., Total, Societal, } \\
\text { Participant, Program } \\
\text { Admin, etc.) }\end{array}$} & \multirow{2}{*}{$\begin{array}{c}\text { Quality } \\
\text { Assurance }\end{array}$} & \multirow[b]{2}{*}{$\begin{array}{l}\text { Process } \\
\text { Feedback }\end{array}$} \\
\hline & $\begin{array}{c}\text { Installs, } \\
\text { Participants } \\
{[\#, \mathrm{~kW}]}\end{array}$ & $\begin{array}{l}\text { Costs, } \\
\text { Budget } \\
{[\text { [\$] }}\end{array}$ & $\begin{array}{l}\text { Partner- } \\
\text { ships [\#] }\end{array}$ & $\begin{array}{l}\text { Jobs } \\
\text { Created } \\
{[\#]}\end{array}$ & $\begin{array}{c}\text { Bill } \\
\text { Reduction } \\
{[\%, \$]}\end{array}$ & $\begin{array}{c}\text { Energy } \\
\text { Burden } \\
{[\%]}\end{array}$ & $\begin{array}{l}\text { Non- } \\
\text { Energy } \\
\text { Impacts }\end{array}$ & $\begin{array}{c}\text { Peak } \\
\text { Reduction } \\
{[\mathrm{kW}]}\end{array}$ & $\begin{array}{l}\text { Gen. } \\
\text { [kWh] }\end{array}$ & Potential & $\begin{array}{l}\text { Demo- } \\
\text { graphics }\end{array}$ & $\begin{array}{l}\text { LI Cross- } \\
\text { Enrollment }\end{array}$ & & & \\
\hline CA: DAC-SASH & $x$ & $x$ & $x$ & $x$ & & & & & $x$ & $x$ & & $x$ & & & $x$ \\
\hline $\begin{array}{l}\text { CA: Green Tariff Shared } \\
\text { Renewables }\end{array}$ & $x$ & $\mathrm{x}$ & $x$ & & & & & & & & $x$ & $x$ & & & \\
\hline $\begin{array}{l}\text { CT: Res. Solar } \\
\text { Investment Prog. (LI } \\
\text { Sub-Progs.) }\end{array}$ & $x$ & & & & $x$ & & & & & & $x$ & & $x$ & & \\
\hline DC: Solar For All & $x$ & $\mathrm{x}$ & & $x$ & & & & & & & & & & & \\
\hline $\begin{array}{l}\text { Hl: Green Energy Money } \\
\text { Saver }\end{array}$ & $\mathrm{x}$ & $x$ & & $\mathrm{x}$ & & & & & $x$ & & $x$ & & & & \\
\hline MN: Solar Rewards & $x$ & $x$ & & & & & & & $x$ & & & & & & \\
\hline $\begin{array}{l}\text { NH: LMI Community } \\
\text { Solar Projects }\end{array}$ & $\mathrm{x}$ & $\mathrm{x}$ & $\mathrm{x}$ & & $x$ & & $x$ & & $x$ & & & $\mathrm{x}$ & & & $\mathrm{x}$ \\
\hline $\begin{array}{l}\text { NJ: Community Solar } \\
\text { Energy Pilot }\end{array}$ & $x$ & & & & & & & & & & & & & & \\
\hline $\begin{array}{l}\text { NY: NY Sun Low Income } \\
\text { Sub-Programs }\end{array}$ & $x$ & $x$ & & & $x$ & & & & $x$ & & & & & $x$ & \\
\hline $\begin{array}{l}\text { CA: Weatherization } \\
\text { Assistance Solar } \\
\text { Programs }\end{array}$ & $x$ & & & $x$ & $x$ & & & & & & & & & & \\
\hline CO: Solar Gardens & $\mathrm{x}$ & $\mathrm{x}$ & & & $\mathrm{x}$ & $x$ & & & $x$ & $x$ & $\mathrm{x}$ & $\mathrm{x}$ & $x$ & & $x$ \\
\hline $\begin{array}{l}\text { CO: Low Income } \\
\text { Community Solar Demo }\end{array}$ & $\mathrm{x}$ & $\mathrm{x}$ & & & $x$ & & & & & $x$ & $x$ & & & & \\
\hline CA: SASH & $x$ & $x$ & & $x$ & $x$ & & $x$ & $\mathrm{x}$ & $x$ & & & $x$ & $\mathrm{x}$ & $x$ & $\mathrm{x}$ \\
\hline CA: MASH & $x$ & $x$ & & $x$ & $x$ & & $x$ & $x$ & $x$ & & & $x$ & $x$ & $x$ & $x$ \\
\hline $\begin{array}{l}\text { CA: Solar on Multifamily } \\
\text { Affordable Homes }\end{array}$ & $x$ & $x$ & & $x$ & & & & & & & $\mathrm{x}$ & $\mathrm{x}$ & & & $x$ \\
\hline IL: Solar For All & $x$ & $x$ & $x$ & $x$ & $x$ & $x$ & $x$ & & $x$ & $x$ & $x$ & $x$ & & & $x$ \\
\hline
\end{tabular}




\subsection{Notable Examples of LMI Solar Evaluations}

The following case studies highlight notable examples of program evaluation. The first, a full evaluation, is the most comprehensive among those we examined, similar to traditional energy efficiency evaluations described in Section 3 . The second combines limited program data on installations with public demographic data to provide greater insight into market impacts. The third incorporates extensive collection of data into program operations, streamlining the process. Following these three, we briefly examine additional examples that include good practices potentially applicable to other LMI solar program evaluations.

\subsubsection{Full Evaluation: California SASH and MASH (2011 and 2015) ${ }^{1}$}

The evaluations of California's single-family and multi-family (SASH and MASH) programs cover cumulative and annual program impacts from the perspective of multiple stakeholders. These evaluations are performed periodically by an independent contractor and consider participant impacts, market analysis, program administrator impacts, and costs and benefits. Because they use a consistent method, this approach facilitates tracking over time and comparisons with other programs and strategies. By using surveys to track process improvements, such evaluations can lead to iterative improvements to the program and evaluation method.

Collectively, these evaluations cover the longest-running (13 years) and highest-budget (\$324 million) LMI solar programs to date, and they are the most comprehensive among the evaluations we reviewed. They demonstrate many best practices and could be a model for other programs that have the budget to include this level of detail. Following are key characteristics of the SASH and MASH evaluations.

\section{General}

- The California Public Utilities Commission oversees a third-party evaluation, performed on an established biennial schedule.

- The evaluations have clear objectives and corresponding metrics.

- The evaluations include recommendations for program improvements, which are worked back into an iterative program design.

- Standardized collection and periodic review allow evaluators to track program impacts over time.

\section{Methods}

- Assessment: Evaluators review program documents and databases in addition to interviewing and surveying multiple stakeholders.

- Quality assurance: Evaluators conduct random photographic and/or in-person inspections of installations, selected via a random-

${ }^{1}$ www.cpuc.ca.gov/general.aspx?id=3043 
sampling process.

- Modeling: Evaluators feed collected data into a proprietary model that predicts total solar production, bill reduction, cost/benefits, and so forth.

\section{What sets the evaluations apart}

- The evaluators use verified solar performance data, collected with field inspections and desk reviews, to train energy-production models.

- The evaluations quantify the economic value of non-energy benefits, running cost/benefit models to measure total costs and benefits and those for participants, the program administrator, and society. Results showed that non-energy benefits served both utilities and participants by reducing bill assistance, arrearages and write-offs for utilities and by reducing homelessness, shutoffs, and more for participants.

- Surveys and interviews of participants and other actors are performed, selected by random-sampling techniques. The results are used to rank issues and provide insight on the most important aspects of the programs.

- By cross-referencing other LMI program databases, the evaluation can discern the potential for the program, and improve eligibility verification and marketing.

- By following standard evaluation practices, the evaluations provide a measure of standardization that enables comparisons over time and to other programs.

- The evaluations use Census data to better understand trends by demographics and location and better contextualize how the program affects adoption patterns.

\subsubsection{Demographic Analysis: Connecticut Green Bank (2019)²}

The Connecticut Green Bank's programs have been evaluated a number of times, both internally and externally. For this example, we use an internal evaluation, Sharing Solar Benefits: Reaching Households in Underserved Communities of Color in Connecticut (Hazlewood, Price, and Basham 2019).

This evaluation combines limited programmatic data (just the participant's date and location of each installation) with publicly available Census data to provide insight on the program's impact on demographic adoption patterns. Although this method cannot result in specific conclusions

${ }^{2}$ ctgreenbank.com/wp-content/uploads/2019/05/Sharing-Solar-Benefits-May2019.pdf 
about individual participants, it generates useful narratives regarding the neighborhoods served by the program. The analysts look at adopters before and after the start of a specific LMI-focused program to see if adoption patterns changed after this treatment (essentially analyzing a control and treatment group side by side). Any program could adapt this low-cost descriptive analysis and combine it with a basic tracking report to provide additional information on demographics. This program focused on race, but programs could look at any neighborhood metric available from public data. We further discuss data-driven strategies for evaluation in Section 5 below. Following are key characteristics of the Connecticut Green Bank evaluation.

\section{General}

- It is a fairly short, one-time evaluation, resulting in a descriptive analysis.

- The evaluation tracks neighborhoods served before and after involvement of a program partner (Posigen) that focuses on LMI engagement, and it compares program participants against the general population.

\section{Methods}

- Impact assessment: Analysts used simple, basic participant tracking data from the program (address, date of participation, subprogram) and combined it with Census block group demographic and income data to understand how LMI neighborhood solar adoption changed with the introduction of Posigen and more specific targeting (using non-LMI solar program participants as a control).

\section{What sets the evaluation apart}

- It focuses on small spatial groups to create narratives about the program's market impacts. Analysts summarize program participation in neighborhoods by income, race, and a cross between the two. Other evaluations tracking market impacts often rely on large areas (e.g., state or territory) or household-specific reports on income. Although many program applications or data may include self-reported income to determine eligibility, they are unlikely to include other demographic data, so this could serve as a proxy for other impact program evaluators.

- This approach is replicable by any program with limited funds as a low-cost way to perform an impact analysis as part of a full evaluation.

- Census data are not limited to income and race, so analyses can be flexible and include other demographics of interest (such as primary language spoken).

- For solar programs with an LMI adder or carve-out, this approach can enable comparison of general and LMI participants by creating control and treatment groups. 


\subsubsection{Data Collection: Hawaii GEM\$ $(2019)^{3}$}

The Green Energy Money \$aver (GEM\$) program, from the Hawaii Green Infrastructure Authority, provides on-bill financing to LMI households for residential solar installations. Because the Authority is a public lending agency, it must adhere to mandatory lending practices, and it is audited by the state Division of Financial Institutions. In order to provide financing, the Authority collects a large amount of customer data, which are combined with other assessments to provide a fairly robust evaluation, despite the small size of the Authority and the program.

Following are key characteristics of the Hawaii GEM\$ evaluation.

\section{General}

- The Authority does extensive data collection and reporting, although very little program evaluation is required.

- Data collection has been an integral part of program design from the beginning.

\section{Methods}

- Basic Tracking: The Authority collects data on household income, credit score, and other factors, which it uses to track progress in reaching certain market segments, such as LMI households.

- Modeling: The analysis includes calculation of energy savings, fuel savings, emission reductions, job creation, and state tax revenues based on the number of solar installations.

\section{What sets the evaluation apart}

- Despite a lack of administrative funds and a staff of only five employees, the Authority collects and publicly reports extensive data on participants to show financial auditors that it follows lending laws and carries a sufficient loan loss reserve. Neither the legislature nor the utility commission have asked for an evaluation, although future funding opportunities may require one.

- Because of the extensive data collected, the GEM\$ program could be suitable for evaluation by outside parties-such as academic researchers-provided privacy regulations are followed.

\footnotetext{
${ }^{3}$ https://gems.hawaii.gov/wp-content/uploads/2019/12/HGIA 2019-Report-to-the-Legislature Final-Approved-1.pdf
} 


\subsubsection{Other Notable Examples}

\section{Emphasis on process to focus on program and evaluation design: Illinois Solar For All $\left(\mathbf{2 0 1 9 , 2 0 2 0 ) ^ { 4 }}\right.$}

- The Illinois Solar for All program is fairly new, but has put a strong emphasis on evaluation. The authorizing statute requires full and iterative evaluations, which could offer robust results and improve program design. The first evaluation focused on the startup process, assessing program and evaluation design. The second evaluation, meant to report on early results, happened after only 5 months of program operation, owing to startup delays, and had no operational projects to evaluate.

\section{Exit strategy: Mass Solar Loan ${ }^{5}$}

- A key goal of the Mass Solar Loan program was to produce data that may increase bank comfort with lending to LMI solar customers in Massachusetts. As the program winds down, it is sharing detailed loan performance data with banks to increase comfort with the LMI market segment and encourage continued financing. Knowledge transfer is an evaluation "best practice," allowing future programs to benefit from past findings. In this case, offering data to combat perceived LMI market risk may help traditional financiers serve this market segment with more-favorable lending terms, helping access upfront capital necessary for solar ownership.

\section{Transparency in progress tracking}

Aggregating data across a program to report in real time requires that contractors, administrators, and data providers have a consistent understanding of which metrics must be tracked, how they are tracked, and a standardized format in which they must be reported. Stating these expectations at program onset and training participants to ensure consistency will allow for a more useful data set. Real-time tracking increases transparency for all stakeholders. Currently, at least three LMI solar programs track and report progress metrics online in real time:

- Mass Solar Loan ${ }^{6}$ reports loan awards, including the income and credit score of recipients.

- California programs report LMI solar metrics to the California Distributed Generation Statistics dashboard. ${ }^{7}$

- Illinois Solar For All ${ }^{8}$ reports the status of applications and projects by subcategory.

${ }^{4}$ www.illinoissfa.com/announcements/2020/04/phase-i-and-phase-ii-evaluation-reports-posted

${ }^{5}$ https://energynews.us/2020/12/17/massachusetts-solar-loans-program-leaves-banks-with-confidence-to-lend/

${ }^{6}$ www. masssolarloan.com/program-performance

${ }^{7}$ www.californiadgstats.ca.gov/charts/li

${ }^{8}$ www.illinoissfa.com/project-dashboard/ 


\subsection{Discussion of Evaluations}

Although there is little standardization in LMI solar program evaluations, some common themes emerge from this review. First, only 16 of the $46 \mathrm{LMI}$ solar programs that we identified shared publicly available evaluation documents. While most programs produced progress reports, few perform full evaluations. The lack of full evaluations stems from the relative youth of most programs, their relatively small budgets, and that program cost recovery is not tied to performance-based metrics.

Nevertheless, some evaluations utilized best practices. For example, recurring evaluations allowed progress tracking over time, while using consistent methods and standard metrics allowed for comparisons with other programs. Some evaluators used random sampling techniques to reduce evaluation costs while still analyzing a representative sample for interviews and/or quality assurance. Quality-assurance checks and standard data collection also provided higher-quality training data for predictive models that were used to estimate impact.

A central tenet of program evaluation is the need to identify program goals and then select corresponding metrics that will help track progress towards those goals. In some cases, LMI solar programs have been created as mandatory set-asides within broader programs, and have not formed separate metrics, analysis, or evaluation techniques to measure LMI-specific progress. In other cases, LMI solar programs may have been pilot programs intended simply to increase solar access for LMI communities or LMI customers. For those programs, it may have been sufficient, given budget and scope, to simply summarize program statistics in compliance documents. However, for programs with more specific goals such as market impacts, economic development, utility grid benefits, customer bill affordability, etc., metrics tailored to these goals would likely require deeper data collection, evaluation, and/or modeling.

While LMI solar programs are similar to non-LMI solar programs or energy efficiency programs, the ways in which they differ should be reflected in both program design and evaluation. Many LMI solar programs have broad and hard-to-quantify goals, such as "equity" and "participation." This suggests that evaluators should focus on collecting qualitative feedback from program administrators and participants via interviews and surveys as well as developing associated quantifiable metrics that can be tracked to support these broader goals. For example, while some programs seek to capture non-energy benefits for program participants, few program evaluations incorporated these benefits qualitatively or quantitatively. Similarly, job creation and retention is often touted as a goal, but only eight programs tracked jobs created and none have tracked retention consistently.

Finally, a number of programs link to other LMI social programs-such as the Supplemental Nutrition Assistance Program-to simplify eligibility and enrollment, estimate market potential, and reduce program administration costs. These linked programs can also aid in the process of evaluation, by providing already-collected data on participants where allowed. 


\section{Data-Driven Strategies for Evaluation}

Section summary: Program evaluators can extend their capabilities with publicly available solar market data. Here, we discuss some relatively straightforward ways to apply public or easily accessible data to LMI solar program evaluation and provide examples in three case studies.

The quality of program evaluation depends on data availability, program design, and the effective use of statistical methods. Here we discuss how evaluators can use program data to evaluate LMI solar programs. Recognizing that many programs lack access to high-quality data, we discuss how evaluators can leverage readily available data in the public domain. We illustrate these approaches through case studies of three LMI solar programs. These case studies show that small program sizes may pose challenges to evaluation in terms of impact estimation, and how publicly available data can be used.

\subsection{Data-Driven Program Evaluation}

As a best practice, data collection should be planned into LMI solar program design, and data should be collected on an ongoing basis throughout program implementation, as described in Section 3. This would involve collecting and analyzing household-level data to yield the most precise estimates of program impacts. However, program administrators face budget constraints that may limit their ability to collect such data. Several accessible solar market data sets can assist program evaluators, including Lawrence Berkeley National Laboratory's Tracking the Sun (TTS), Stanford University's Deep Solar, and the National Renewable Energy Laboratory's Solar for All map. ${ }^{9}$

Where evaluators lack access to high-quality household-level demographics data, they can instead use geographically aggregated data (e.g., U.S. Census American Community Survey data) (Figure 6). Data should be aggregated at the smallest geographic unit with available data (e.g., Census tract, zip code). Such "location-based" evaluations can be effective for LMI solar programs given that household demographic characteristics spatially correlate: households tend to resemble their neighbors in terms of demographic characteristics such as income (Reardon and Bischoff 2010). Spatial correlation allows evaluators to make reasonable inferences about LMI solar program impacts without knowing the characteristics of specific households. Location-based evaluations are inherently less precise than household-level assessments, however, so evaluators must be transparent about the limitations of such approaches when expressing levels of confidence in estimated program impacts (Soobader et al. 2001).

\footnotetext{
${ }^{9}$ For more information on these resources see emp.lbl.gov/tracking-the-sun, web.stanford.edu/group/deepsolar/home, and maps.nrel.gov/solar-for-all, respectively.
} 


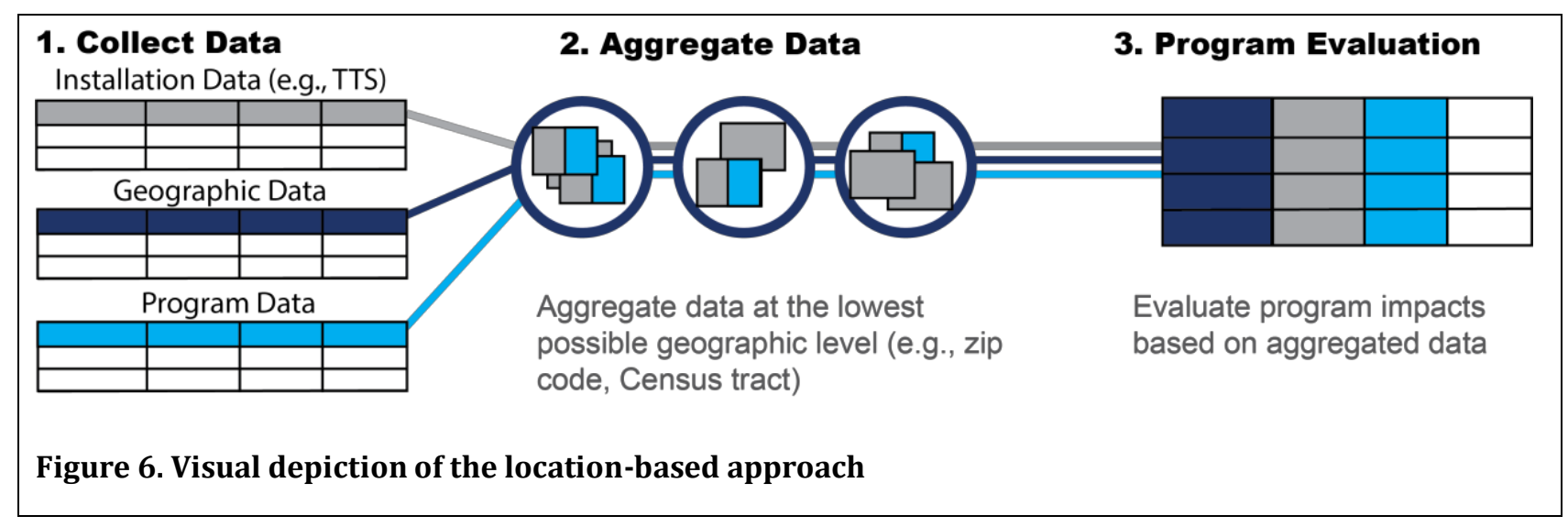

Although each evaluation is unique, the steps depicted in Figure 7 represent a common framework. After data have been compiled, a next and crucial step is to identify a treatment group (households that received LMI incentives) and a comparable control group (households that did not receive incentives). Extraneous differences between treatment and control groups can confound results. Statistical techniques such as propensity score matching can mitigate these confounding factors and help evaluators identify comparable treatment and control groups.

Many evaluations use simple descriptive analyses to compare differences between the treatment and control groups. Descriptive analyses assess correlations in the data without attempting to control for potentially confounding factors. Descriptive analyses can yield useful and relatively intuitive insights into program impacts. At the same time, descriptive analyses should be treated with caution, because perceived differences may reflect confounding factors. A variety of econometric methods allow evaluators to identify program impacts while accounting for these confounding factors. The most common program evaluation identification methods are defined and summarized in Appendix D. A comprehensive review of program evaluation identification methods is available in the literature (Abadie and Cattaneo 2018). 


Identification
$\begin{aligned} & \text { Collect data for } \\ & \text { observations that have and } \\ & \text { have not received LMI } \\ & \text { incentives }\end{aligned}$
$\begin{aligned} & \text { Festrict sample to } \\ & \text { comparable treatment and } \\ & \text { control groups (e.g., } \\ & \text { statistical matching) }\end{aligned}$

\subsection{Case Studies}

To illustrate the household-level and location-based approaches, we present analyses of LMI solar case studies in California, Connecticut, and New York (Table 5). The location-based approaches use publicly available data from TTS and the Census, while the household-level approaches use a combination of publicly available data (TTS, Census) and proprietary data from Barbose et al. (2020). ${ }^{10}$ In both cases, we use propensity score matching to identify treatment and control groups (see Appendix D).

Table 5. LMI Solar Program Case Studies

\begin{tabular}{|l|l|l|}
\hline \multicolumn{1}{|c|}{ Program } & \multicolumn{1}{c|}{ Eligibility } & \multicolumn{1}{c|}{ Data Sample } \\
\hline CA SASH & $80 \%$ area median income & 9,161 systems \\
\hline CT Solar For All & $100 \%$ area median income & 811 systems \\
\hline NY Affordable Solar & $80 \%$ area median income & 412 systems \\
\hline
\end{tabular}

10 TTS is the most comprehensive source of U.S. distributed solar market data. The complete data set covers more than $80 \%$ of the U.S. solar market. Barbose et al. (2020) describes the household-level estimates and modeled income data. 


\subsubsection{Descriptive Analyses}

For the household-level approach, we analyze the impacts of the three programs in terms of differences in adopter income bias: the difference between a solar adopter's annual income and the adopter's county's median income level. We use county median income as the closest available proxy for the area median incomes used to determine LMI program eligibility in the case studies (area median income is based on household size, but we do not know household size in the data). Most solar adopters in these states earn more than their county median income (Figure 8), for a positive income bias. However, people who receive LMI incentives exhibit significantly less income bias than nonrecipients. About half of LMI incentive recipients in California and Connecticut have negative income bias, earning less than their county median income. ${ }^{11}$ These descriptive results confirm that LMI incentives are flowing toward LMI solar adopters.
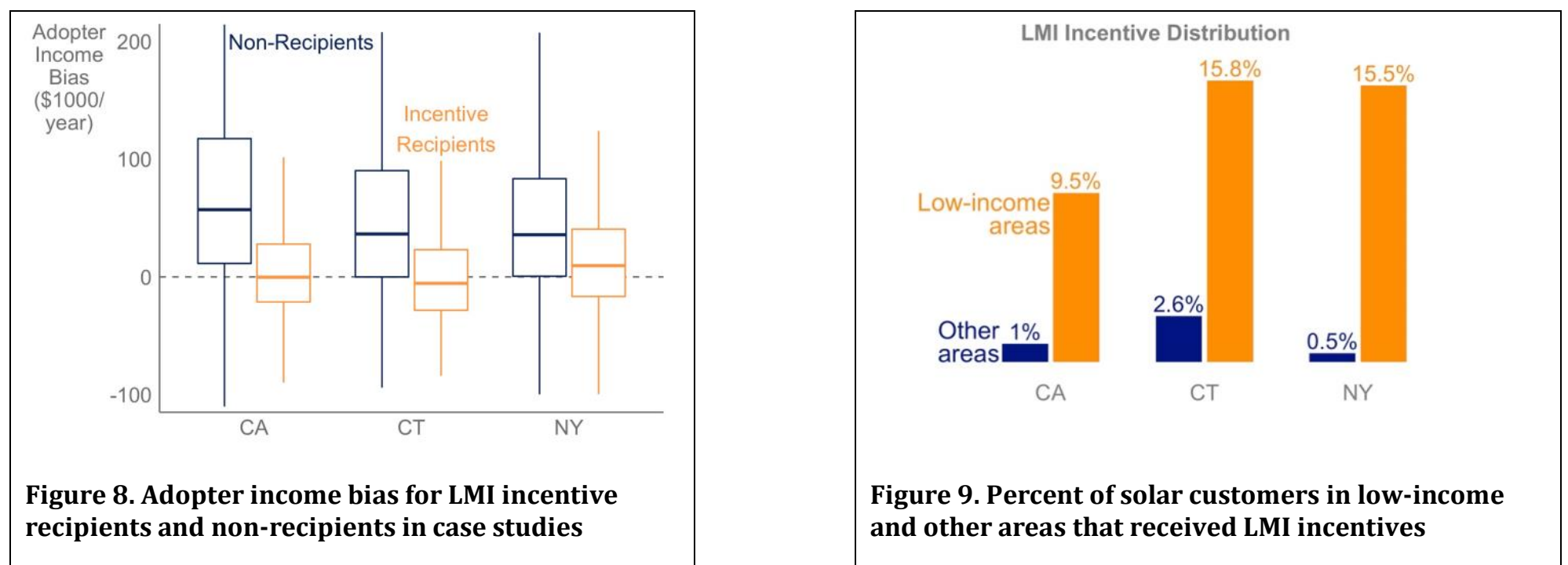

For the location-based analysis, we use Census data to identify zip codes in the bottom quartile of median incomes in each state. We then use

${ }^{11}$ The data suggest that some LMI incentive recipients earn more than their county median income. This result has two explanations. First, program eligibility is generally based on area median income thresholds determined by family size. In these case studies, we do not have access to family size, therefore some households may earn more than the county median income but still qualify for LMI incentives based on family size-defined area median incomes. Second, like all modeled data, the modeled income estimates include some modeling error. The fact that modeled incomes for LMI incentive recipients center around zero provide evidence the incentives flow to LMI households. 
the public TTS data to compare LMI incentive distribution levels in LMI zip codes versus other areas. The data show that LMI incentives in all three states flow disproportionately to households in LMI communities (Figure 9). ${ }^{12}$ For instance, the data suggest that about $16 \%$ of adopters in LMI communities in Connecticut received LMI incentives, compared to about $2.6 \%$ of adopters in other areas. Put another way, adopters in LMI communities were about 6 times more likely to receive LMI incentives. Because households tend to resemble their neighbors in terms of income, race, and other demographic factors, these results suggest that LMI incentives are flowing to LMI solar adopters, confirming the household-level analysis.

\subsubsection{Identification}

Optimal identification methods vary based on program design and data limitations. With enough foresight and resources, LMI solar programs can be designed for evaluation, such as through quasi-random distribution of the LMI incentives (Violette and Rathbun 2017). Further, there is ideally a clear before/after demarcation in the distribution of incentives, which would facilitate common identification methods such as differences-in-differences (DiD) (see Appendix D). In reality, such before/after demarcations are rare. Our three case studies are illustrative. In all three, LMI incentives were distributed over time at varying rates in different locations rather than in a clear before/after fashion.

Similar to the method described and implemented in O'Shaughnessy et al. (2020), we evaluate our case studies using a special DiD method that addresses staggered deployment, known as the group-time model (Callaway and Sant'Anna 2019). See Appendix D for methodological details. For the household-level approach, we use the group-time model to test the impacts of LMI solar programs on LMI solar adoption rates: the number of LMI solar adopters per 1,000 LMI households measured at the zip code level. Figure 10 illustrates the results. The group-time models suggest that LMI adoption rates would range from around 0.4 installs per 1,000 households in New York to 1.6 in California in the absence of incentives. These are the "counterfactual" rates illustrated in Figure 10. In each state, the model attributes increased LMI adoption rates to the LMI incentives. In the first quarter in which incentives are distributed, the model suggests that LMI adoption rates increased by about 2.3 additional LMI installs per 1,000 households in California, 0.9 additional installs in Connecticut, and 1.2 additional installs in New York.

12 The "other areas" refer to zip codes outside the control group. See Appendix D. 

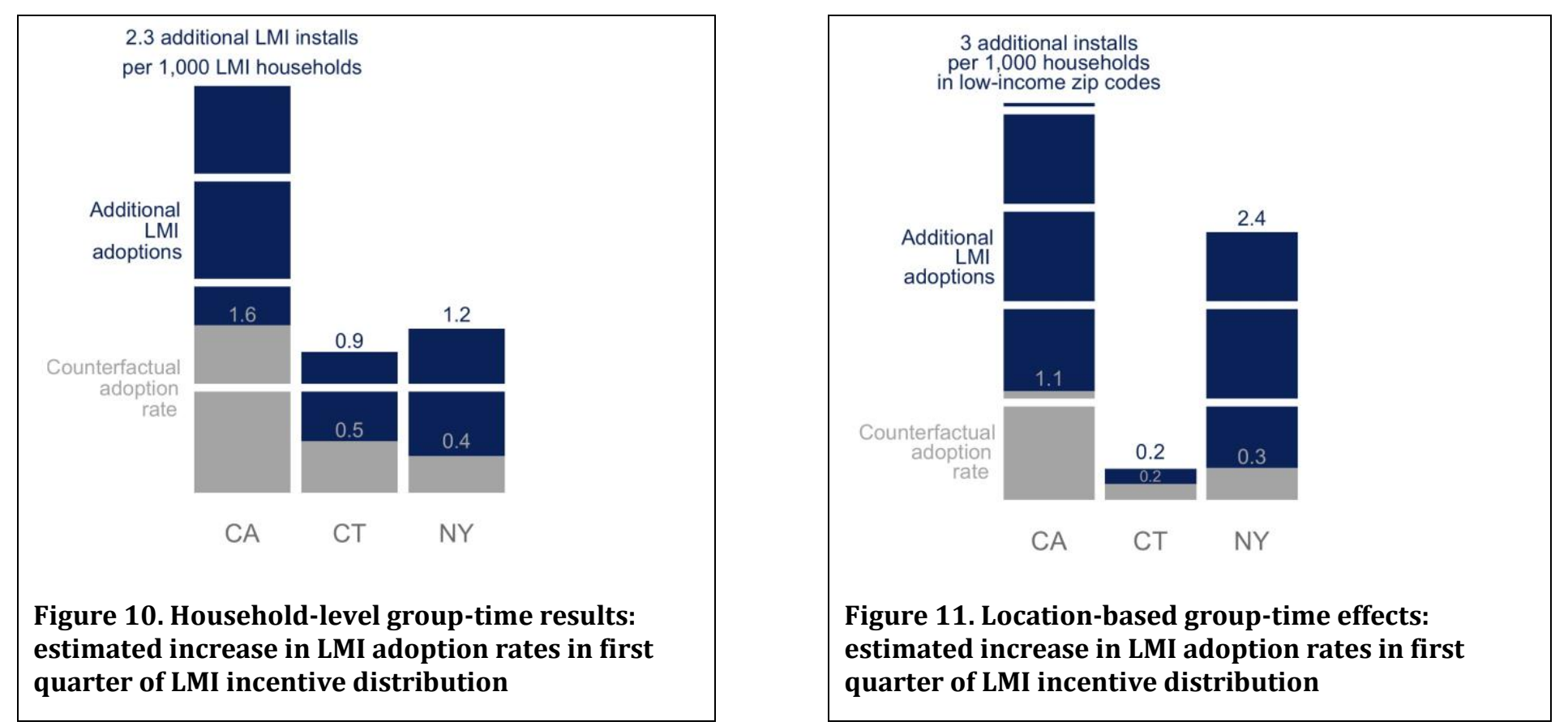

Figure notes: The gray boxes represent the expected "counterfactual” LMI adoption rates (installs per 1,000 households) in the absence of the LMI incentives. The gray and blue boxes represent the actual observed LMI adoption rates. Hence, the blue boxes represent the additional LMI adoption attributed to the LMI incentives.

For the location-based approach, we test the impacts of incentives on solar adoption rates in LMI zip codes (those in the bottom quartile of median incomes in each state). Figure 11 illustrates the results. The model estimates counterfactual adoption rates (in the absence of incentives) ranging from 0.2 installs per 1,000 households in low-income zip codes in Connecticut to 1.1 installs in California. The model suggests that incentives significantly increase adoption rates in low-income zip codes in the first quarter that incentives are distributed, with effects ranging from an additional 0.2 installs per 1,000 households in Connecticut, to 2.4 additional installs in New York and 3 additional installs in California.

\subsubsection{Case Study Key Takeaways}

The case study results are presented for illustrative purposes. Nonetheless, these illustrative results provide two key takeaways for future LMI solar program evaluations. 


\section{Small programs equate to small impacts}

Although most of the measured impacts are statistically significant-particularly when all three case studies are analyzed together-the impacts are small in absolute terms. As a first-order approximation, the group-time models suggest that LMI solar programs result in one additional LMI solar installation per quarter in each zip code where incentives are available. This estimate must be considered in the context of LMI solar program size. The California program - the largest of the three case studies-invested about $\$ 132$ million in about $30 \mathrm{MW}$ of LMI solar systems (GRID Alternatives 2020), compared to a statewide installed capacity of about 8,000 MW. Suppose for illustrative purposes that California dedicated the same $\$ 132$ million directly to buying LMI solar systems (i.e., excluding program administrative costs and cost sharing from incentive recipients) at current California system prices (about $\$ 3.8 / \mathrm{W}$ ). With that budget, the program could incentivize around $35 \mathrm{MW}$ of LMI solar system capacity, well under $1 \%$ of the capacity projected to be installed in California over the next few years. Even with cost sharing, incentive distribution is likely to remain around $1 \%$ of total market size under a comparable budget. These simple heuristics illustrate that LMI solar program impacts are inherently constrained by program budgets, and that small programs equate to small impacts.

From an evaluation perspective, the key implication of small program sizes is that broader program impacts will be inherently difficult to detect. For instance, the average group-time impact of the California case study-based on more than 9,000 LMI incentive recipients-has a p-value of just $4 \%$, barely clearing the standard $5 \%$ bar for statistical significance. As a result, some caution is required in the interpretation of LMI solar program evaluation results. Statistically insignificant results do not necessarily mean that LMI solar programs do not have an impact; they could simply indicate that the available data sample was too small to statistically detect the impact. Small programs may require multiple years of data collection before program impacts can be detected statistically.

\section{Readily accessible data can supplement program data}

We presented the results of household-level and location-based analyses for three case studies. The household-level results are more precise, likely providing a better approximation of true program impacts. Assuming that is the case, the location-based analyses slightly overestimate program impacts in California and New York and underestimate impacts in Connecticut. Nonetheless, the location-based approach-based entirely on readily accessible public data-supports the same high-level conclusions as the household-level analysis: LMI incentives accrue to LMI households, and LMI solar programs are associated with higher rates of LMI solar adoption.

The case studies demonstrate how readily accessible data can supplement program data in program evaluation. Evaluators can feel comfortable using location-based approaches to provide first-order approximations of program impacts. As a best practice, evaluators should present location-based results with appropriate caveats and urge readers to interpret the numerical values of the results with caution (Soobader et al. 2001) 


\section{Conclusions, Key Themes, and Best Practices}

Solar adoption could alleviate LMI household energy burdens. However, despite falling solar costs, LMI households remain significantly less likely to adopt solar. Dozens of states, utilities, and local jurisdictions are exploring and implementing LMI solar programs that include financing, upfront and production incentives, and mandatory set-asides to address solar adoption inequity for LMI homeowners, tenants, and communities.

Program evaluation is key to identify and prioritize LMI solar program designs that maximize LMI household energy and non-energy benefits and help to achieve policy goals in renewable energy and equity. In this study, we identify 46 programs across the U.S., 41 of which are currently active. Of those, we found 16 programs with publicly available evaluation documents. We conducted a meta-evaluation of these 16 program evaluations, along with 8 supplemental interviews of key program stakeholders, to better understand trends in LMI solar goals, evaluation methods, and key metrics. To conclude our study, we summarize 5 key themes and 6 best practices that emerged and offer some closing thoughts for program administrators and policymakers.

\subsection{Key Themes}

\subsubsection{The majority of LMI solar programs do not have publicly-available evaluations}

Of the 46 identified LMI solar programs, we reviewed evaluation documents for 16 of them. While all programs track (or will track) progress in some way, not all evaluate impacts or outcomes, and not all share their results. In some cases, where the LMI solar program was a mandatory set-aside of a larger solar program, LMI-specific evaluation was not always separated out and analyzed. In other cases where a program was new or in-progress, evaluations had not yet been performed, though they may be forthcoming as more experience is gained. Finally, some programs are small enough that spending limited program dollars on a rigorous evaluation cannot be justified.

In some programs, the policy goal was simply to ensure that public funds used to promote solar power were shared by all income classes. Accordingly, the simple metrics used and lack of deeper evaluation simply reflect the goal. Secondary goals of reducing energy burdens, fighting poverty, and creating green jobs were implied, but not explicitly tracked.

\subsubsection{Some programs conduct progress reports, but few conduct true program evaluations}

Of the 16 programs with published evaluations, all conduct periodic progress reports for regulatory filings summarizing simple metrics such as program expenditures and installed solar capacity. However, of those 16 programs, only 4 have conducted true program evaluations 
comparable to those common for energy efficiency. Further, even the large program evaluations are primarily descriptive in nature, i.e., the evaluations do not use statistical techniques to isolate program impacts. The paucity of in-depth LMI solar program evaluations likely reflect program design and budget constraints.

\subsubsection{Evaluations use a variety of metrics}

LMI solar program evaluations describe program impacts using a variety of metrics. Of 15 programs with defined metrics, the number of systems installed was the most common metric (16/16). Other common metrics included expenditures (13/16), jobs created (8/16), bill reduction (9/16), and solar system output $(9 / 16)$.

\subsubsection{Programs vary in the extent to which data collection and evaluation are factored into program design}

LMI solar programs designed with high-level goals often lack specific plans for data collection or in-depth program evaluations. In contrast, a few programs have clear and specific goals and have aligned those goals with quantifiable metrics and complementary qualitative survey data collection to better understand program impact. These programs were designed with specific plans for periodic, consistent program evaluations that allow for iterative improvements to the program itself and tracking over time. For instance, the California programs include periodic evaluations and the Illinois Solar For All program has focused on program design with designated funding for future program evaluations.

\subsubsection{Programs can extend evaluation capabilities through publicly-available data}

Limited program budgets and data collection could explain the lack of in-depth LMI solar program evaluations. Nonetheless, even budgetconstrained programs can extend their evaluation capabilities by coupling program data with publicly-available demographic and solar market data. For instance, a Connecticut program evaluation leveraged U.S. Census data to measure program impacts on LMI solar adoption. In Section 5 , we summarize how other programs could apply similar methods.

\subsection{Best Practices}

Through our review of existing LMI solar program evaluations, the program evaluation literature, and interviews with program stakeholders, we identified 6 categories of best practices for LMI solar program evaluation. The categories are intended for program administrators, evaluators, policymakers, and other stakeholders.

\subsubsection{Continuous Evaluation}

Evaluation is often considered a final "report card" after program completion. It is sometimes performed before deciding whether to continue 
or expand a program, such as transitioning from a pilot to a full launch. However, evaluation can also be continuous, providing real-time feedback on the achievement of program goals and facilitating continuous improvement. This is most often done with progress trackers or internal evaluations. To provide continuous feedback, starting points (such as preexisting solar penetration levels) should be assessed before the program launches, and a system of data collection should be implemented along with the program. These steps also lower the cost and improve the quality of a formal post hoc evaluation.

Example: Program dashboards such as California Distributed Generation Statistics can provide constant feedback, even if they just track basic metrics (e.g., applications, rebates) rather than analyzing trends, explaining outcomes, identifying free riders, and so forth. In some cases, progress trackers are shared online with the public, which helps keep stakeholders apprised of progress and helps vendors plan for changing opportunities.

\subsubsection{Applying Best Practices from Other Fields}

Due to budget constraints and program goals that may differ from traditional solar or energy efficiency programs, LMI solar program design and evaluation often differ from best practices developed in other sectors. For example, efficiency programs are often required to have a stated program theory with specific interventions intended to mitigate specified market barriers. Especially in the case of mandatory set-asides or pilot programs, LMI solar program goals are rarely as explicit in their theory of change. This can affect their program design, data collection, and evaluation process.

There are a few best practices that could be implemented in LMI solar program evaluation, regardless of budget or scope. These practices could include establishing clear and specific goals that drive metrics, conducting evaluations and engaging relevant stakeholders, consistency and transparency in data reporting, and leveraging relationships with other LMI programs, among others.

Example: California's SASH and MASH programs centered program design around LMI-specific targets. Going further than high-level goals such as "increased LMI solar adoption", they set goals around energy affordability, job creation, market transformation, etc. Likely due to the longevity of the programs and high levels of funding, program administrators were able to design data collection strategies around these goals. While they are thorough in their investigations, they conduct evaluations every few years and employ random data sampling to reduce the overall burden and complexity of evaluation. Conducted by a third party, they have been able to collect quantitative and qualitative data from multiple stakeholders including utilities, installers, and customers. Moreover, built into their evaluation are feedback loops to improve process and program design. For example, an earlier evaluation found that participants particularly were interested in non-energy benefits, so they designed metrics and began tracking these. Additional changes made directly from evaluation results include changes in data reporting and 
marketing. Though many programs are far younger and smaller than California's, ensuring tight alignment of program goals and metrics tracked, requiring consistency in data collection and reporting, and allowing for results from evaluations to feed back into program design can improve the process for any program.

\subsubsection{Collecting Multi-Dimensional Data}

Many programs only track whether participants meet eligibility requirements. But limited data collection results in limited analytical capabilities. Collecting more types of data creates more opportunities to analyze statistical relationships. For instance, evaluators could explore whether customer characteristics such as income, age, or race correlate with program benefits.

Example: The 2011 California SASH evaluation assessed how participants responded to marketing channels according to household language and income. Spanish-speaking households were notably different than other participants, relying for advice much more on friends and relatives and not at all on their utility (Cooney, Solomon, and Palermo 2011).

\subsubsection{Standardizing LMI Solar Program Evaluation}

Over the decades, energy efficiency program evaluation protocols have become sophisticated and standardized, facilitating progress tracking, program comparisons, and budget accountability. With few exceptions, LMI solar evaluations have not followed these protocols; rather, they have been tailored to individual programs. This may reflect immediate program needs, unique program designs, and limited budgets, but it hinders comparison and aggregation of results across multiple programs. As LMI solar programs mature, they would benefit from standard methods and data that facilitate comparisons.

Example: Standard methods for evaluating LMI solar programs would improve the quality and rigor of evaluations and could streamline the evaluation process. The Environmental Protection Agency has worked with state and utility stakeholders to develop standard practices for energy efficiency program evaluation, as have many states (US EPA 2019), resulting in clear formal methods such as the participant cost test. The same could be done for LMI solar programs, or states could be helped to develop more rigorous evaluation practices.

\subsubsection{Integrating Non-Energy Benefits}

Non-energy benefits are a key goal of LMI solar programs, yet they are rarely measured in evaluations. They are becoming more common in energy efficiency program evaluations, and methods exist to estimate their values, such as interviewing program administrators and participants (Sutter et al. 2020). Non-energy benefits especially important to LMI solar programs can include the following: 
- Job training and job creation for LMI workers

- Increased homeowner wealth through solar ownership

- Increased participation in the energy transition (e.g., "Solar for All")

- Better engagement with underserved communities

- Remediation of environmental injustices and housing/lending discrimination

- Energy resilience (especially when combined with storage)

Example: Better quantifying non-energy benefits could change perceptions about the value of LMI solar program strategies. For example, rooftop solar increases property values and thus increases the wealth of the homeowner. If an LMI solar program aims to increase LMI household wealth, such impacts should be included in evaluations.

\subsubsection{The Importance of Process Evaluations}

Although impact evaluations can find the bottom-line outcomes of greatest interest to officials, stakeholders, and the public, they do not always explain how success (or failure) was achieved. Process evaluations help provide the explanations (Freeman, Campbell, and Harms 2016).

Solar adoption is affected by many exogenous factors, such as the marketing practices of solar companies, utility rates, economic trends, and grid-reliability problems. A process evaluation can help distinguish program effects from the effects of such outside factors. It is critical for improving program operations and enhancing future impacts, especially for programs that are nascent or experimental.

Process evaluations are designed to answer key questions related to program performance: Which program marketing and outreach campaigns were most successful? Which customer education or solar installer trainings were most effective? Were incentive levels high enough to encourage LMI participation? What barriers to LMI customer participation has the program yet to mitigate? Process evaluations can also use benchmarking approaches to judge LMI solar program performance within a broader context. For example, they can compare the customer participation rates of two programs and identify the factors that led to different results.

Example: Washington DC presents challenges to solar deployment because of its old building stock, completely built urban environment, abundance of multi-family housing, and LMI tenants who live in master-metered buildings or are subject to U.S. Department of Housing and Urban Development (HUD) rules on rent and utilities. Within this context, Washington DC's Solar For All program started with a 3-year period of "innovation and expansion," testing nine program approaches through a series of grants. Process evaluations of each approach will enable the administrators to identify effective aspects with the goal of improving future program implementations. 


\subsection{Closing Thoughts}

This meta-evaluation suggests that more LMI solar programs could benefit from evaluation in general. From there, we identify several best practices that could be applied by program administrators. If program goals and evaluation budgets are clearly defined in advance, data collection and evaluation can be planned and implemented accordingly from the beginning of the program. Building the collection of data (especially demographic data) into program operations can reduce costs and improve evaluation later while providing real-time feedback for continuous improvement of program implementation.

On the other hand, new goals and outcomes may emerge as experimental or nascent programs are implemented, leading to new data needs. In such cases, many policymakers have kept initial efforts small through pilot projects, followed by careful evaluations. Washington DC's Solar for All is one program that planned experimentation and evaluation into a pilot stage.

Low-cost methods of data collection and analysis that rely on public data sources can be applied to improve evaluations of smaller programs. Research has shown that Census data at the block or block-group level are a reasonably good substitute for specific household-level demographic information.

Evaluations often seem like an afterthought or a report card at program completion, but a good, timely evaluation can provide measurable insights into critical questions and reduce reliance on assumptions. Evaluation results can feed back into program design and implementation as well as the fundamental policy questions that spurred program initiation. The following are questions to ask of the evaluation process:

- Do the evaluations answer fundamental questions about a program related to its use by intended beneficiaries, its cost-effectiveness, its strategies for overcoming barriers, and so forth?

- Is a given program the best use of public funds? Can evaluations help compare various strategies aimed at the same outcomes, both in energy or non-energy fields?

- Are the evaluations timely, actionable, and transparent enough to enable continuous improvement and stakeholder engagement, or are they done too late to shape success?

As solar power becomes more cost-effective, mainstream, and market-perpetuated, the rationale for public spending on solar may shift from simply commercializing a new technology to ensuring that all sectors of society can benefit from it. Evaluating programs and documenting best practices could be critical to guiding future funding decisions. 


\section{References}

Abadie, Alberto, and Matias D. Cattaneo. 2018. “Econometric Methods for Program Evaluation.” Annual Review of Economics 10 (1): $465-503$. https://doi.org/10.1146/annurev-economics-080217-053402.

Bednar, Dominic J., and Tony G. Reames. 2020. "Recognition of and Response to Energy Poverty in the United States." Nature Energy 5 (6): $432-$ 39. https://doi.org/10.1038/s41560-020-0582-0.

Brown, Marilyn Ann, Anmol Soni, Melissa Voss Lapsa, and Katie Southworth. 2020. "Low-Income Energy Affordability: Conclusions From A Literature Review." ORNL/TM-2019/1150, 1607178. https://doi.org/10.2172/1607178.

Callaway, Brantly, and Pedro H. C. Sant'Anna. 2019. “Difference-in-Differences with Multiple Time Periods.” SSRN Scholarly Paper ID 3148250. Rochester, NY: Social Science Research Network. https://doi.org/10.2139/ssrn.3148250.

Cooney, Kevin, Jane Pater Solomon, and Erin Palermo. 2011. "California Solar Initiative Low-Income Solar Program Evaluation: Market Assessment Report." Navigant Consulting. https://www.cpuc.ca.gov/WorkArea/DownloadAsset.aspx?id=4286.

Freeman, Luisa, Bradley Campbell, and Samuel Harms. 2016. "Evaluating Your Utility's Energy Services Programs: Market Research and Evaluation for Energy Efficiency Professionals." American Public Power Association (APPA).

GRID Alternatives. 2020. "California: Single-Family Affordable Solar Homes (SASH) Program, Semi-Annual Progress Report."

Hazlewood, Isabelle, Selya Price, and Emily Basham. 2019. "Connecticut: Sharing Solar Benefits: Reaching Households in Underserved Communities of Color in Connecticut." https://ctgreenbank.com/wp-content/uploads/2019/05/Sharing-Solar-Benefits-May2019.pdf.

Leon, Warren, Chandra Farley, Nate Hausman, Berneece Herbert, and Nicole Hernandez Hammer. 2019. "Solar with Justice: Strategies for Powering Up Under-Resourced Communities and Growing an Inclusive Solar Market." https://www.cesa.org/resourcelibrary/resource/solar-with-justice/.

Schiller, Steve. 2012. "Energy Efficiency Program Impact Evaluation Guide." State and Local Energy Efficiency Action Network. https://www7.eere.energy.gov/seeaction/system/files/documents/emv_ee_program_impact_guide_0.pdf.

Soobader, Mah-jabeen, Felicia Le Clere, Wilbur Hadden, and Brooke Maury. 2001. "Using Aggregate Geographic Data to Proxy Individual Socioeconomic Status: Does Size Matter?" American Journal of Public Health Vol. 91 (No. 4). https://www.ncbi.nlm.nih.gov/pmc/articles/PMC1446644/.

Sutter, Mary, Jenn Mitchell-Jackson, Steve Schiller, Lisa Schwartz, and lan Hoffman. 2020. "Applying Non-Energy Impacts from Other Jurisdictions in Cost-Benefit Analyses of Energy Efficiency Programs: Resources for States for Utility Customer-Funded Programs." Lawrence Berkeley National Laboratory. https://eta-publications.Ibl.gov/sites/default/files/nei_report_20200414_final.pdf. 
Tonn, Bruce, Erin Rose, Beth Hawkins, and Brian Conlon. 2014. "Health and Household-Related Benefits Attributable to the Weatherization Assistance Program." ORNL/TM-2014/345. Oak Ridge National Lab.

US EPA. 2008. "Understanding Cost-Effectiveness of Energy Efficiency Programs." 1219678. US Environmental Protection Agency. https://doi.org/10.2172/1219678.

- - - 2019. "Guidebook for Energy Efficiency Evaluation, Measurement, and Verification." https://www.epa.gov/sites/production/files/201906/documents/guidebook_for_energy_efficiency_evaluation_measurement_verification.pdf.

Violette, Daniel M., and Pamela Rathbun. 2017. "Chapter 21: Estimating Net Savings - Common Practices. The Uniform Methods Project: Methods for Determining Energy Efficiency Savings for Specific Measures." NREL/SR--7A40-68578, 1408086. The Uniform Methods Project: Methods for Determining Energy Efficiency Savings for Specific Measures. NREL. https://doi.org/10.2172/1408086. 


\section{Appendix A. Interview Summaries}

Video conference interviews with program administrators were conducted in November 2020.

\section{A.1. California SASH and MASH}

GRID Alternatives administers California's single-family LMI solar programs (SASH and DAC-SASH) and co-administers the multi-family program (SOMAH). These are the largest and longest-running U.S. programs, dating back to 2007. SASH has spent \$290 million to date, while DAC-SASH is budgeted at $\$ 120$ million over the coming decade. SOMAH's budget could total $\$ 1$ billion over a decade, while the preceding MASH program spent $\$ 162$ million on incentives. These very large budgets resulted in well-funded and rigorous evaluations that most closely match those consistent with full energy efficiency evaluations.

GRID Alternatives reports progress data weekly to the California Distributed Generation Statistics website to provide near real-time reporting. In annual reports to the Public Utilities Commission, GRID Alternatives summarizes progress data and discusses challenges. It uses blogs and press releases to advertise successes-a form of case study.

SASH has been evaluated twice (every 3 years) by Navigant, with a third evaluation underway. SOMAH is undergoing its first review by Itron, looking mostly at the startup process. The Navigant evaluations were two- or three-volume sets, examining administrator performance,

program impacts, cost, and benefit and providing a market assessment. According to GRID Alternatives, the 2015 SASH evaluation was a notable improvement, because it incorporated non-energy benefits to better reflect program goals. This is an example of how evaluations can create a feedback loop to improve program and evaluation design.

Despite the rigor of the program evaluations, GRID Alternatives sees potential for improvement. It would like to track outcomes from job training over time, add data monitoring to older installed systems, track system performance through end of warranty, and get more information on tenants of multi-family housing served by the SOMAH program. 


\section{A.2. Illinois Solar for All}

Solar For All provides incentives for on-site single- and multi-family housing, community solar, and public and nonprofit facilities. It launched in 2018, and some sectors are oversold while others are seeing little response. It is managed by Elevate Energy.

Even though Solar For All has delivered few results yet, it has been evaluated twice, as required by statute. The first covered the startup, including "the stakeholder outreach process, development of program materials and guidelines, initial Approved Vendor (AV) registration, initial project application, and the development of Grassroots Education." The second covered only the first 5 months of program operation, so it was too soon to have useful results, according to Elevate Energy. For example, the winning community solar projects have 18 months to enroll customers, so customer benefits were not part of the evaluation. More useful in guiding the program have been interviews with vendors and grassroots groups. Elevate Energy submits quarterly and annual progress reports to the state public utilities commission.

\section{A.3. DC Solar for All}

The Washington DC solar program is necessarily complex, given the many difficulties of deploying solar there. It is a $100 \%$ urban environment, with many aging and federally owned buildings, many multi-family homes, many master-metered apartment buildings, and many LMI households in HUD-regulated housing facing the constraint of HUD utility allowances. Washington DC also has very aggressive solar mandates (100\% renewable by $2032,50 \%$ solar by 2041 ), resulting in very high Solar Renewable Energy Certificate prices, which serve as a financial tool to overcome deployment obstacles.

As a result, the Solar For All program's first 3 years were a period of "innovation and expansion," where a variety of ideas were tested, including how to deliver benefits to tenants in a master-metered apartment building who are constrained by HUD rules, how to market to commercial property owners, and what partnerships are most fruitful.

For evaluations, Solar For All submits an annual report to the City Council tracking progress, undergoes an external quality assurance/control process with an outside party, and is audited by the city auditing agency. The program has awarded nine grants, and the grantees are required to report results. The program has evaluated the financing of projects that have been built but does not yet have performance data.

The program hopes to finish an internal "lessons learned" evaluation of the innovation and expansion stage next year, which will guide program direction. Solar for All runs through 2032, and evaluation plans include annual key performance indicator reports, a data dashboard with energy 
production and participating households, and future evaluations influenced by the 2021 report. According to program representatives, "It's a very fluid situation due to many things that can change."

\section{A.4. Solarize Philly}

Solarize Philly is a group purchasing program run by the Philadelphia Energy Agency (PEA) since 2017. It has signed more than 650 contracts, making it potentially the largest U.S. solarize campaign. PEA charges a fee for participation, with the funds used to subsidize installations on 45 LMI homes to date. The LMI installations provide a minimum savings of $20 \%$ in year 1 , and ownership of the system transfers to the customer after 15 years.

In its public reports, PEA tracks dollars invested, megawatts installed, number of signups, number of contracts, and jobs created. It compares LMI installation costs with market-rate costs. It also administers a customer satisfaction survey for participants and collects household income and FICO credit scores to determine the size of its loan loss reserve. It does not plan to track bill impacts, over concerns about privacy and the complications of performing a bill analysis.

A primary goal of PEA's evaluation strategy is to know if its LMI solar approach is scalable: How much installation cost was paid by the customer or other sources (such as tax credits), and thus how much leverage does program money have, and how long will its funds last?

\section{A.5. Mass Solar Loan}

The Mass Solar Loan program, which ended in 2020, encouraged Massachusetts banks and credit unions to offer solar loans for LMI customers. To facilitate these loans, the program gave LMI customers a package of incentives including a $1.5 \%$ interest rate buy down, a $30 \%$ reduction in the loan principal (up to $\$ 10,500$ per household), and an additional loan loss reserve incentive for customers with poor credit scores. While the program was originally open to all customers, in recent years it focused only on LMI customers. It was open to both property owners and renters, although the vast majority of participants were property owners.

There were no requirements for external evaluations of Mass Solar Loan. However, program staff reported doing internal evaluations. They surveyed all program participants 2 weeks after project installations, gauging customer satisfaction and collecting demographic information (such as age and education level). The program also regularly submitted program performance statistics to state regulators, which are available through public records requests. This includes anonymized information on the performance of the LMI solar loans. 
Because the program ended in 2020, program staff have been compiling lessons learned. They plan to share the information with participating banks and credit unions, to encourage them to continue serving LMI customer segments.

Program staff identified questions about program performance that deserved further study, possibly by a third-party evaluator. One is whether Mass Solar Loan helped participating installers reach LMI customers who they would not have reached without the program. Another was whether the package of incentives that the program offered was effective in encouraging LMI projects, and whether a different mix or amount of incentives would have been equally effective.

\section{A.6. Connecticut Green Bank's Solar for All}

Connecticut Green Bank offers two channels for encouraging solar adoption in underserved markets. One, first offered in 2014, is an elevated LMI solar incentive paid directly to the LMI owner of the solar system. It is available to customers who earn less than $100 \%$ of area median income. In 2015, the program added a Solar for All 20-year solar leasing option for LMI homeowners, which is offered by the program's dedicated provider PosiGen. Connecticut Green Bank markets this Solar for All product in underserved communities and provides significant financing to PosiGen to subsidize the product.

Connecticut Green Bank has been involved with several third-party evaluations of its LMI programs. In 2018, Opinion Dynamics completed an evaluation of the PosiGen solar lease component based on two online surveys of participating customers. The surveys covered sources of program awareness, motivations for joining the program, barriers to participation, levels of energy efficiency activity, estimated energy savings, and program satisfaction. Opinion Dynamics also developed a program attribution algorithm for measuring free ridership based on these online surveys. In 2019, Navigant completed a benefit-cost analysis of Connecticut Green Bank's energy storage systems. In 2020, with funding from the U.S. Department of Energy, Lawrence Berkeley National Laboratory performed a financial analysis of the program. The program also worked with The Nielsen Company on a segmentation/profiling study of LMI customers to help identify which customer types were more likely to adopt solar. The program shared the study findings with Connecticut solar installers. Finally, the program is subject to yearly external audits of its financial management practices.

Connecticut Green Bank has recently reduced its budgets for external evaluations. Program staff believe they can adequately analyze program performance in-house using detailed program data they have collected over the years. For example, they are calculating how much customers in the PosiGen solar lease program are saving on their energy bills by combining metered data on actual system performance with retail electric 
rates and then subtracting out the costs of lease payments. This is part of a general state trend to move away from deemed energy savings estimates towards data-driven estimates. They have also been involved in studies looking at the broader cost burdens of Connecticut LMI customers beyond the traditional energy cost burden. The program surveys customers a few months after joining the program, but program staff have not recently analyzed these survey data.

\section{A.7. NJ Community Solar Pilot Program}

In 2019, the New Jersey Community Solar Pilot Program conducted its first competitive solicitation for community solar projects with 75 MW of capacity available. It scored these proposed projects based on several criteria, including LMI participation. All 45 projects eventually selected were LMI projects, which meant that at least $51 \%$ of their subscribers would be LMI customers. As of September 2020, none of the projects were operating commercially yet, although a few were under construction. The COVID-19 pandemic has led nearly all projects to request exemptions from program requirements that construction must be started within 6 months of award.

The program has yet to do any external evaluations. Program staff reported that they were monitoring closely this initial cohort of projects to extract lessons learned that they can address when designing future program iterations. They are collecting these lessons learned through informal conversations rather than a formal, structured interview process. However, the staff are using the bi-monthly review of project requests for extensions of the construction deadline as an opportunity to "check in" with each project.

Once the first cohort of projects is ready to come online and the New Jersey utilities receive the list of subscribers for bill credit purposes, the program plans to begin a verification process to ensure that projects are meeting their LMI requirements. A New Jersey stakeholder group is looking at possible barriers to LMI customer recruitment, such as excessive income verification requirements for vendors. The program is currently not collecting any demographic information about participating customers; vendors are required only to collect income information to verify eligibility and historical household consumption information to avoid oversizing the systems.

\section{A.8. Hawaii GEM\$}

The Green Energy Money \$aver (GEM\$) program, from the Hawaii Green Infrastructure Authority, provides on-bill financing to LMI households for residential solar installations. It is capitalized by a $\$ 150$ million bond floated in 2014 . Because it is a public agency, it must adhere to mandatory lending practices and consumer protection measures, and it is audited by annually by third-party CPA firms. 
Data collection has been an integral part of program design from the beginning. The agency collects data on household income, energy consumption, and other factors, and it calculates estimated energy savings, fuel savings, job creation, and state tax revenues resulting from solar installations.

Despite a staff of only five employees, the Authority collects and publicly reports extensive data on projects financed. Governed by a board, the Authority submits quarterly reports to the Hawaii Public Utilities Commission and annual reports to the Governor and Legislature on program progress and impacts. They have not to date been required to do a full evaluation. 


\section{Appendix B. Directory of LMI Solar Programs}

This table is a directory to $46 \mathrm{LMI}$ solar program in the United States as of June 2020 (41 active or upcoming and 5 inactive) with the state in which they operate/d, target sector, program elements, eligibility criteria, and years of operation. Tables are organized by state and starting year.

\section{B.1. $\quad$ Active LMI Solar Programs}

\begin{tabular}{|c|c|c|c|c|c|}
\hline Program & State & Sector & Program Elements & Eligibility Criteria & Starting Year \\
\hline Community Solar Pilot Program & CA & CS & Incentive & $\begin{array}{l}80 \% \text { Area Median Income, or } \\
\text { located in Disadvantage Community }\end{array}$ & 2019 \\
\hline $\begin{array}{l}\text { Solar on Multifamily Affordable } \\
\text { Housing (SOMAH) }\end{array}$ & $\mathrm{CA}$ & MF & $\begin{array}{l}\text { Incentive, } \\
\text { Mandatory Set-Aside }\end{array}$ & $\begin{array}{l}60 \% \text { Area Median Income, and } \\
\text { located in Disadvantaged Community }\end{array}$ & 2019 \\
\hline $\begin{array}{l}\text { Disadvantaged Communities - Green } \\
\text { Tariff (DAC-GT) }\end{array}$ & $\mathrm{CA}$ & CS & Incentive & $\begin{array}{l}\text { CARE or FERA eligibility ( } 250 \% \text { Federal } \\
\text { Poverty Level), and } \\
\text { located in Disadvantaged Community }\end{array}$ & 2018 \\
\hline Community Solar Green Tariff (CSGT) & CA & CS & $\begin{array}{l}\text { Mandatory } \\
\text { Set-Aside }\end{array}$ & $\begin{array}{l}\text { CARE or FERA eligibility ( } 250 \% \text { Federal } \\
\text { Poverty Level), and } \\
\text { located in Disadvantaged Community }\end{array}$ & 2018 \\
\hline $\begin{array}{l}\text { CA Disadvantaged Communities-Single } \\
\text { Family Affordable Solar Housing (DAC- } \\
\text { SASH) }\end{array}$ & CA & SF & Incentive & $\begin{array}{l}\text { CARE or FERA eligibility ( } 250 \% \text { Federal } \\
\text { Poverty Level), and } \\
\text { located in Disadvantaged Community }\end{array}$ & 2018 \\
\hline $\begin{array}{l}\text { Green Tariff / Shared Renewables in } \\
\text { Disadvantaged Communities (GTSR- } \\
\text { DAC) }\end{array}$ & $\mathrm{CA}$ & CS & Mandatory Set-Aside & $\begin{array}{l}\text { CARE or FERA eligibility ( } 250 \% \text { Federal } \\
\text { Poverty Level), and } \\
\text { located in Disadvantaged Community }\end{array}$ & 2016 \\
\hline Low Income Weatherization Program & CA & $\begin{array}{l}\mathrm{CS}, \mathrm{SF} \\
\mathrm{MF}\end{array}$ & Incentive & $60 \%$ State Median Income & 2014 \\
\hline GoSolarSF Program & CA & SF & Incentive & $\begin{array}{l}80 \% \text { Area Median Income, or } \\
\text { located in Disadvantaged Community }\end{array}$ & 2007 \\
\hline
\end{tabular}




\begin{tabular}{|c|c|c|c|c|c|}
\hline $\begin{array}{l}\text { CA Single Family Affordable Solar } \\
\text { Housing (SASH) }\end{array}$ & $\mathrm{CA}$ & SF & Incentive & $80 \%$ Area Median Income & 2007 \\
\hline CO Community Solar Gardens Act & $\mathrm{CO}$ & CS & Mandatory Set-Aside & 185\% Federal Poverty Level & 2010 \\
\hline $\begin{array}{l}\text { Boulder CO Solar Rebate and Grant } \\
\text { Programs }\end{array}$ & $\mathrm{CO}$ & $\begin{array}{l}\text { SF, MF, } \\
\text { NGO }\end{array}$ & Incentive & $\begin{array}{l}\text { Gross income limits (by household size): } \\
\text { e.g., } \$ 82,880 \text { (3-person) }\end{array}$ & 2006 \\
\hline $\begin{array}{l}\text { Connecticut Shared Clean Energy } \\
\text { Facility (SCEF) }\end{array}$ & $\mathrm{CT}$ & CS & Mandatory Set-Aside & TBD & 2019 \\
\hline $\begin{array}{l}\text { Conn Green Bank Low Income } \\
\text { Multifamily Energy (LIME) Loan } \\
\text { Program }\end{array}$ & $\mathrm{CT}$ & $\mathrm{MF}$ & Financing & $80 \%$ Area Median Income & 2015 \\
\hline $\begin{array}{l}\text { CT Residential Solar Investment } \\
\text { Program (RSIP) }\end{array}$ & $\mathrm{CT}$ & SF & Incentive & 100\% Area Median Income & 2014 \\
\hline DC Solar for All & DC & $\begin{array}{l}\mathrm{CS}, \mathrm{SF} \\
\mathrm{MF}\end{array}$ & Incentive & $80 \%$ Area Median Income & 2017 \\
\hline FPL SolarTogether & $\mathrm{FL}$ & CS & Mandatory Set-Aside & 200\% Federal Poverty Level & 2019 \\
\hline $\begin{array}{l}\text { HI Community-Based Renewable } \\
\text { Energy }\end{array}$ & $\mathrm{HI}$ & CS & Mandatory Set-Aside & $80 \%$ Area Median Income & 2020 \\
\hline Green Energy Money \$aver on-bill & $\mathrm{HI}$ & $\mathrm{SF}, \mathrm{MF}$ & Financing & 140\% Area Median Income & 2014 \\
\hline Illinois Solar For All & IL & $\begin{array}{l}\text { CS, SF, } \\
\text { MF, } \\
\text { NGO }\end{array}$ & $\begin{array}{l}\text { Incentive, } \\
\text { Mandatory Set-Aside }\end{array}$ & $80 \%$ Area Median Income & 2019 \\
\hline MA-SMART & MA & $\begin{array}{l}\mathrm{CS}, \mathrm{SF} \\
\mathrm{MF}\end{array}$ & Mandatory Set-Aside & $65 \%$ State Median Income & 2018 \\
\hline Mass Solar Loan & $\mathrm{MA}$ & SF & Financing & $80 \%$ State Median Income & 2015 \\
\hline MD Community Solar & MD & CS & Mandatory Set-Aside & 175\% Federal Poverty Level & 2017 \\
\hline $\begin{array}{l}\text { Residential Community Solar Grant } \\
\text { Program }\end{array}$ & MD & CS & Incentive & 175\% Federal Poverty Level & 2017 \\
\hline$\underline{\text { Xcel Energy Solar Rewards program }}$ & $\mathrm{MN}$ & $\begin{array}{l}\mathrm{CS}, \mathrm{SF} \\
\mathrm{MF} \\
\mathrm{NGO}\end{array}$ & Incentive & $\begin{array}{l}50 \% \text { State Median Income, or } \\
200 \% \text { Federal Poverty Level }\end{array}$ & 2019 \\
\hline
\end{tabular}




\begin{tabular}{|c|c|c|c|c|c|}
\hline $\begin{array}{l}\text { Connecting Low-Income Communities } \\
\text { through Efficiency and Renewable } \\
\text { Sources (CLICERS) roadmap }\end{array}$ & $\mathrm{MN}$ & CS, SF & Incentive & $50 \%$ State Median Income & 2018 \\
\hline $\begin{array}{l}\text { Minnesota Power Low Income Solar } \\
\text { Pilot Program }\end{array}$ & $\mathrm{MN}$ & & Incentive & $\begin{array}{l}\text { Greater of: } 50 \% \text { State Median Income, or } \\
110 \% \text { Federal Poverty Level }\end{array}$ & 2017 \\
\hline$\underline{\text { NEM LMI adder }}$ & $\mathrm{MS}$ & SF & Incentive & 200\% Federal Poverty Level & 2016 \\
\hline $\begin{array}{l}\text { New Hampshire Low Income } \\
\text { Community Solar }\end{array}$ & $\mathrm{NH}$ & CS & Mandatory Set-Aside & 300\% Federal Poverty Level & 2018 \\
\hline NJ Community Solar Pilot & NJ & CS & Mandatory Set-Aside & $200 \%$ Federal Poverty Level & 2019 \\
\hline $\begin{array}{l}\text { NV Energy Lower Income Solar Energy } \\
\text { Program }\end{array}$ & NV & $\begin{array}{l}\mathrm{MF} \\
\mathrm{NGO}\end{array}$ & Incentive & $\begin{array}{l}\text { Federal Low Income Housing Tax Credit } \\
\text { qualifier, or Business serving significant LMI } \\
\text { population }\end{array}$ & 2013 \\
\hline Lower Income Solar Energy Program & NV & $\mathrm{MF}$ & Incentive & $\begin{array}{l}\text { Federal Low Income Housing Tax Credit } \\
\text { qualifier }\end{array}$ & 2013 \\
\hline $\begin{array}{l}\text { PSEG Long Island Solar Communities } \\
\text { program }\end{array}$ & NY & CS & Mandatory Set-Aside & TBD & 2020 \\
\hline NYSERDA Solar for All community solar & NY & CS & Incentive & $60 \%$ State Median Income & 2018 \\
\hline NY-Sun Affordable Solar & NY & $\mathrm{SF}, \mathrm{MF}$ & Incentive & $80 \%$ Area Median Income & 2010 \\
\hline OR Community Solar & OR & CS & Mandatory Set-Aside & $\begin{array}{l}80 \% \text { Area Median Income, or } \\
80 \% \text { State Median Income }\end{array}$ & 2019 \\
\hline PEA Solar Savings Grant Program & $\mathrm{PA}$ & $\mathrm{SF}, \mathrm{MF}$ & Incentive & $80 \%$ Area Median Income & 2017 \\
\hline$\underline{\text { RI Community Renewables }}$ & RI & CS & Incentive & SNAP, LIHEAP, or SSI qualifier & 2019 \\
\hline$\underline{\text { SC Shared Solar }}$ & SC & CS & Incentive & 200\% Federal Poverty Level & 2018 \\
\hline Dominion SC Community Solar & SC & CS & Incentive & 200\% Federal Poverty Level & 2017 \\
\hline Virginia Shared Solar & VA & CS & Mandatory Set-Aside & $80 \%$ Area Median Income & 2021 \\
\hline $\begin{array}{l}\text { Low-Income Community Solar } \\
\text { Deployment (LICSD) grants }\end{array}$ & WA & $\mathrm{CS}$ & Incentive & Varies by installation & 2020 \\
\hline
\end{tabular}




\section{B.2. Inactive LMI Solar Programs}

\begin{tabular}{|c|c|c|c|c|c|}
\hline Program & State & Sector* & Program Elements & Eligibility Criteria & Years Active \\
\hline $\begin{array}{l}\text { CA Multi-Family Affordable Solar } \\
\text { Housing (MASH) }\end{array}$ & CA & MF & Incentive & CA-defined affordable housing & $2009-2018$ \\
\hline $\begin{array}{l}\text { Colorado Low-Income Community Solar } \\
\text { Demonstration Project }\end{array}$ & $\mathrm{CO}$ & CS & Incentive & Varies by pilot's qualifying agency & $2015-2017$ \\
\hline $\begin{array}{l}\text { Colorado Rooftop Low-Income } \\
\text { Program, part of Weatherization } \\
\text { Assistance Program (WAP) }\end{array}$ & $\mathrm{CO}$ & SF & Incentive & $60 \%$ State Median Income & 2017 \\
\hline $\begin{array}{l}\text { Connecticut Shared Clean Energy } \\
\text { Facility (SCEF) Pilot }\end{array}$ & CT & CS & $\begin{array}{l}\text { Mandatory } \\
\text { Set-Aside }\end{array}$ & $\begin{array}{l}\text { Greater of: } 80 \% \text { State Median Income, } \\
80 \% \text { Area Median Income, or } \\
\text { 175\% Federal Poverty Level }\end{array}$ & 2016-2018 \\
\hline $\begin{array}{l}\text { Connecting Low-Income Communities } \\
\text { through Efficiency and Renewable } \\
\text { Sources (CLICERS) roadmap }\end{array}$ & $\mathrm{MN}$ & $\mathrm{CS}, \mathrm{SF}$ & Incentive & $50 \%$ State Median Income & 2018/TBD \\
\hline Community solar for community action & MN, VT & CS & Incentive & 150\% Federal Poverty Level & Varies \\
\hline
\end{tabular}




\section{Appendix C. Directory of LMI Solar Program Evaluations Reviewed for this Report}

Progress reports and evaluations from the following programs were evaluated for this review.

\begin{tabular}{|c|c|c|c|}
\hline State & Program & Author & Title and Link \\
\hline CA & $\begin{array}{l}\text { Single-Family Affordable } \\
\text { Solar Housing (SASH) }\end{array}$ & GRID & $\underline{\text { SASH Semi-Annual Progress Reports }}$ \\
\hline CA & $\begin{array}{l}\text { Disadvantaged } \\
\text { Communities SASH } \\
\text { (DAC-SASH) }\end{array}$ & GRID & Semi-annual program reports \\
\hline CA & $\begin{array}{l}\text { Multi-Family Affordable } \\
\text { Solar Housing (MASH) }\end{array}$ & California IOUs & MASH Semi-Annual Progress Reports \\
\hline CA & $\begin{array}{l}\text { California Solar Initiative } \\
\text { (MASH and SASH) }\end{array}$ & Navigant & $\begin{array}{l}\text { CSI Low-Income Solar Program Evaluation: Market Assessment Report, } \\
\text { Program Impacts and Cost-Benefit Report, and Program Administrator } \\
\text { Performance Assessment Report (2011) }\end{array}$ \\
\hline CA & $\begin{array}{l}\text { California Solar Initiative } \\
\text { (MASH and SASH) }\end{array}$ & Navigant & $\begin{array}{l}\text { CSI SASH and MASH Market and Program Administrator Assessment, } \\
\text { and Impact and Cost-Benefit Analysis, Programs Years 2011-2013, } \\
\underline{(2015)}\end{array}$ \\
\hline CA & $\begin{array}{l}\text { Solar on Multifamily } \\
\text { Affordable Homes } \\
\text { (SOMAH) }\end{array}$ & ILLUME & SOMAH Phase1 Evaluation: Final Report \\
\hline CA & $\begin{array}{l}\text { Green Tariff Shared } \\
\text { Renewables }\end{array}$ & California IOUs & Annual program reports \\
\hline CA & $\begin{array}{l}\text { Low-Income } \\
\text { Weatherization Program } \\
\text { (LIWP) }\end{array}$ & $\begin{array}{l}\text { CA Department of } \\
\text { Community Services and } \\
\text { Development }\end{array}$ & Low-Income Weatherization Program (LIWP) Impact Report \\
\hline $\mathrm{CO}$ & Colorado Low Income & Lotus & Insights from the Colorado Energy Office Low-Income Community Solar \\
\hline
\end{tabular}




\begin{tabular}{|c|c|c|c|}
\hline & Community Solar Demo & & Demonstration Project \\
\hline CO & Colorado Solar Gardens & Lotus & $\begin{array}{l}\text { Analysis of the Fulfillment of the Low-Income Carve-Out for Community } \\
\text { Solar Subscriber Organizations }\end{array}$ \\
\hline CT & $\begin{array}{l}\text { Residential Solar } \\
\text { Investment Program } \\
\text { (RSIP) }\end{array}$ & $\begin{array}{l}\text { Connecticut Center for } \\
\text { Economic Analysis, University } \\
\text { of Connecticut }\end{array}$ & $\begin{array}{l}\text { Connecticut Green Bank's Residential Solar Investment Program: } \\
\text { Economic Impact Analysis of Existing Commitments and Future } \\
\underline{\text { Scenarios }}\end{array}$ \\
\hline CT & $\begin{array}{l}\text { Residential Solar } \\
\text { Investment Program } \\
\text { (RSIP) }\end{array}$ & Cadmus & $\begin{array}{l}\text { Connecticut: Cost-Effectiveness Assessment of the Residential Solar } \\
\text { Investment Program and Residential Solar Investment Program } \\
\text { Evaluation (January } 30,2015 \text { ) }\end{array}$ \\
\hline CT & $\begin{array}{l}\text { Residential Solar } \\
\text { Investment Program } \\
\text { (RSIP) }\end{array}$ & Connecticut Green Bank & $\begin{array}{l}\text { Sharing Solar Benefits: Reaching Households in Underserved } \\
\text { Communities of Color in Connecticut }\end{array}$ \\
\hline DC & DC Solar For All & $\begin{array}{l}\text { DC Dept of Energy \& } \\
\text { Environment }\end{array}$ & DC Solar for All Annual Report October 1, 2018 - September 30, 2019 \\
\hline HI & $\begin{array}{l}\text { Green Energy Money } \\
\text { \$aver }\end{array}$ & $\begin{array}{l}\text { Hawaii Green Infrastructure } \\
\text { Authority }\end{array}$ & 2019 Annual Report to the Governor and Legislature \\
\hline IL & IL Solar For All & Apprise & $\begin{array}{l}\text { Illinois Solar For All Phase I Evaluation: Final Report and Phase II } \\
\text { Evaluation: Final First Interim Report }\end{array}$ \\
\hline MN & Solar Rewards & Xcel & 2019 Annual Report: Solar*Rewards Docket No. E002/M-13-1015 \\
\hline NH & $\begin{array}{l}\text { Low-Moderate Income } \\
\text { Community Solar } \\
\text { Projects }\end{array}$ & NH PUC & Costs and Benefits Report (2020) \\
\hline NJ & $\begin{array}{l}\text { Community Solar Energy } \\
\text { Pilot }\end{array}$ & NJ BPU & $\underline{\text { New Jersey's Community Solar Energy Pilot Program }}$ \\
\hline NY & $\begin{array}{l}\text { NY Sun Low Income Sub- } \\
\text { Programs }\end{array}$ & NYSERDA & $\begin{array}{l}\text { NY-Sun Annual Performance Report } \\
\underline{\text { through December 31, } 2019}\end{array}$ \\
\hline
\end{tabular}




\section{Appendix D. Methodology for Data-Driven Evaluation Strategies}

\section{D.1. Identification Methods}

Table C-1 summarizes the four most common program identification methods.

Table C-1. Program Evaluation Identification Methods

\begin{tabular}{|l|l|l|}
\hline $\begin{array}{l}\text { Identification } \\
\text { Method }\end{array}$ & Description & $\begin{array}{l}\text { Strengths (+) / } \\
\text { Weaknesses (-) }\end{array}$ \\
\hline $\begin{array}{l}\text { Conditioning on } \\
\text { variables }\end{array}$ & $\begin{array}{l}\text { This is a standard regression controlling for potentially } \\
\text { confounding observable variables. The ideal set of } \\
\text { control variables will vary by program, but may include } \\
\text { observable variables such as median area incomes, } \\
\text { population density, rates of home ownership, and other } \\
\text { factors that could simultaneously correlate with LMI } \\
\text { solar program implementation and outcomes. }\end{array}$ & $\begin{array}{l}\text { + It is easy to implement. } \\
\text { - It requires strong assumptions that observed variables can } \\
\text { completely control for confounding factors. Even with a large } \\
\text { underlying unobserved confounding variation that could bias } \\
\text { estimates of program effects. }\end{array}$ \\
\hline $\begin{array}{l}\text { Differences-in- } \\
\text { differences } \\
\text { (DiD) }\end{array}$ & $\begin{array}{l}\text { DiD models evaluate changes in the differences } \\
\text { between treatment and control groups over time. A } \\
\text { change in the differences in outcomes provides the } \\
\text { evidence of program effects under the DiD approach. }\end{array}$ & $\begin{array}{l}\text { + When the "common trends" assumption holds (see below), } \\
\text { DiD can isolate program impacts even without exhaustive } \\
\text { data on potentially confounding variables. }\end{array}$ \\
\hline Discontinuity & $\begin{array}{l}\text { These models leverage discontinuities in treatment that } \\
\text { could control for confounding factors. Income } \\
\text { thresholds for LMI incentive eligibility are an example of }\end{array}$ & $\begin{array}{l}\text { - DiD requires the common trends assumption that the } \\
\text { trends in treatment and control groups would have been } \\
\text { identical in the absence of treatment. The validity of the } \\
\text { common trends assumption rests on identifying a valid } \\
\text { control group that approximates the trend in LMI adoption } \\
\text { rates absent an incentive program. }\end{array}$ \\
\hline $\begin{array}{l}\text { + Discontinuities can yield similar treatment and control } \\
\text { treatment. For instance, households just above and below an }\end{array}$ \\
\hline
\end{tabular}




\begin{tabular}{|c|c|c|}
\hline & $\begin{array}{l}\text { a treatment discontinuity. } \\
\text { In theory, discontinuity design could be an effective } \\
\text { approach for certain aspects of LMI solar program } \\
\text { evaluation. }\end{array}$ & $\begin{array}{l}\text { LMI incentive income threshold are likely similar in many } \\
\text { regards. } \\
\text { - Discontinuity design requires relatively precise data in } \\
\text { order to effectively restrict analyses to a small subset of } \\
\text { observations near the discontinuity. The precision required } \\
\text { may be difficult to obtain through modeled household-level } \\
\text { data or geographically aggregated data. }\end{array}$ \\
\hline $\begin{array}{l}\text { Instrumental } \\
\text { variables }\end{array}$ & $\begin{array}{l}\text { An instrument is a variable that correlates with an } \\
\text { explanatory variable (e.g., LMI incentives) but does not } \\
\text { correlate with an outcome (e.g., LMI adoption rates) } \\
\text { when conditioned on the explanatory variable. }\end{array}$ & $\begin{array}{l}\text { + Instrumental variables can correct biases resulting from } \\
\text { unobserved confounding factors or simultaneous causality } \\
\text { between dependent and independent variables. } \\
\text { - The primary challenge of instrumental variables is } \\
\text { identifying a valid instrument that meets the exclusion } \\
\text { restriction: The instrument must not correlate with the } \\
\text { desired outcome, at least when conditioned on the } \\
\text { explanatory variable or other variables in the model. }\end{array}$ \\
\hline
\end{tabular}

\section{D.2. Case Studies}

We defined treatment groups as zip codes where at least one household received an LMI incentive. All zip codes where no households received LMI incentives were candidates for the control group. We used propensity score matching to identify proportional numbers of zip codes as controls in each case study. Zip codes were matched based on populations of owner-occupied LMI households, median income levels, solar market density (installations/household), and the percentage of solar-viable rooftop space in the zip code based on Google Project Sunroof data. We used the Matchlt package in R to implement the matching. Note that the descriptive analysis of the location-based data (Figure 9) uses unmatched data. In that case, all matched zip codes were LMI zip codes. For illustrative purposes, we compared LMI incentive distribution in LMI zip codes (treatment group) to other areas outside the control group.

The group-time DiD models used the following dependent variables based on the data approach:

- Household-level data: LMI adoption rates at the zip code level (LMI adoption/1,000 LMI households in zip code). 
- Location-based approach: Adoption rates in LMI zip codes by county (adoptions in LMI zip codes/1,000 households in LMI zip codes).

As a result of these two approaches, we compiled both zip code- and county-level data sets.

To identify program impacts, we used a variant of DiD developed by Callaway and Sant'Anna (2019). The "group-time" model measures heterogenous DiD effects across groups and across time. In our case, each group is a cohort of zip codes that began receiving LMI incentives in the same quarter. Like other DiD models, the key identifying assumption is that trends in the treatment and control groups would have been the same without the intervention (LMI incentives). See O'Shaughnessy et al. (2020) for discussion of this assumption in the context of LMI incentive program evaluation.

Our group-time model takes the following form:

$$
r=\sigma_{g, t}+\tau_{g, t} G_{g}+\rho_{g, t} T_{t}+\beta_{g, t} G_{g} T_{t}+\gamma X+\varepsilon_{g, t}
$$

Where $r$ is the solar penetration rate in LMI zip codes in the case of the location-based model and the LMI household solar penetration rate in the case of the household-level model, $G_{g}$ is an indicator variable for the group of counties/zip codes that first began receiving incentives in quarter $g, T_{t}$ is an indicator variable for quarter $t, G_{g} T_{t}$ is an interaction of the two terms, and $X$ is a vector of controls for median income and number of households in each county/zip code. The household-level model also controls for the number of non-LMI adoptions per quarter per zip code. We used the DiD package in $\mathrm{R}$ to implement the group-time model.

The coefficient $\beta_{g, t}$ measures the average treatment effect for group $g$ at time $t$. The results depicted in Figure 10 and Figure 11 are based on the average value for $\beta_{g, t}$ across groups when the time period $t$ is equal to the first period that each group received LMI incentives. For instance, the value for the California program in Figure 10 can be interpreted in plain language as follows: on average, LMI adoption rates increased by about 2.3 installations per 1,000 LMI households per quarter in the first quarter when zip codes began receiving incentives. 